MARC VAN DE VELDE

\title{
ZUR WORTSTELLUNG IM NIEDERLÄNDISCHEN UND
}

\author{
IM DEUTSCHEN SATZ*
}

\section{Einführung}

0.1. In der deutschen Syntax wird der Wortstellung im allgemeinen und der Satzklammer (siehe 0.2.) im besonderen große Aufmerksamkeit gewidmet. Das läßt sich leicht dadurch erklären, daß die Satzklammer als ein typisches Merkmal des deutschen Satzbaus betrachtet wird, wie z.B. aus folgendem Zitat hervorgeht:

"Natürlich gehört eine nicht unbeträch tliche gedankliche Kraft dazu, um mit solchen Satzbauplänen richtig umzugehen. Und das führt uns auf einen wichtigen Gedanken: wenn diesem Gesetz der Umklammerung in der deutschen Sprache eine so weite Wirkung zukommt, dann ist das gewiß nicht nur die Folge davon, daß die so zusammengefügten Gedankengebilde den Deutschen in dieser Form von draußen entgegenträten, sondern weit mehr die Ursache dafür, daß sie ihre Gedanken auf solchen Wegen gestalten. Diese Satzbaupläne gehören durchaus dem Weltbild der deutschen Sprache an. Man kann sich leicht davon überzeugen, wenn man die Satzbaupläne der Nachbarsprachen heranzieht." (Weisgerber, 1967, S. 387)

Weisgerber wird hier wohl an erster Stelle an das Englische und das Französische gedacht haben, die den verbalen Komplex zusammenhalten. Was er und auch andere deutsche Sprachwissenschaftler aber nicht zu wissen schienen, nämlich daß der Satz im Niederländischen dasselbe Bauprinzip kennt wie im Deutschen, hatte F. Bodmer schon genau beschrieben (1961, S. 155 ff.).

* Oberarbeitete Fassung von: De structuur van de zin in het Nederlands en het Duits, in: Studia Germanica Gandensia XII (1970), S. 179-218.

Herzlicher Dank gebührt Herrn G. De Schutter, Gent, dessen Anmerkungen zu einer ersten Fassung dieses Aufsatzes für mich von großem Wert waren, und Herrn U. Engel und Frau U. Hoberg, Mannheim, die den Text sprachlich überprüften. 
Der erste niederländische Sprachwissenschaftler, der diese "Besonderheit des Niederländischen und des Deutschen" explizit behandelte, war C.B. Van Haeringen. Er betrachtete sie vom Standpunkt der Zweckmäßigkeit aus und nannte sie sehr beschwerlich und unpraktisch (1947, S. 3).

Aus diesen beiden Aussagen geht deutlich hervor, wie eine Spracherscheinung auf vollkommen verschiedene Weisen bewertet werden kann.

0.2. Die Satzklammer und die weitere Einteilung des Satzes in Stellungsfelder

0.2.1. Bei der Untersuchung der Wortstellung im Satz zeigt sich, daß die verbalen Elemente im Niederländischen und im Deutschen eine relativ feste Stellung haben: so steht das finite Verb im Formhauptsatz normalerweise an zweiter Stelle; die infiniten Teile einer zusammengesetzten Verbalgruppe stehen am Ende des Satzes; mit dem finiten Verb bilden sie die Klammer, so zal/wird und brengen/bringen in:

in bet vervolg zal bij $u$ altijd naar buis brengen na bet werk In Zukunft wird er Sie immer nach Hause bringen nach der Arbeit

Wenn man von der Stellung der Verbformen ausgeht, könnte man wie U. Engel (1970a, S. 39 ff.) 3 Stellungsfelder im Satz unterscheiden:

- was vor dem finiten Verb steht (Vorfeld)

- was zwischen dem finiten Verb und dem (den) infiniten Verbteil(en) steht (Mittelfeld)

- was nach dem (den) infiniten Verbteil(en) steht (Nachfeld)

Außer den Verbformen haben aber auch noch andere, nichtverbale Elemente eine relativ feste Stellung im Satz. So kommen wir, indem wir uns auf die von G. De Schutter (1967) ergänzte und berichtigte Einteilung von P.C. Paardekooper (1955) stützen, zu 5 Stellungsfeldern. Das oben angeführte Beispiel wird dann wie folgt aufgegliedert:

\begin{tabular}{|l|l|l|l|l|}
\multicolumn{1}{c}{1} & 2 & 3 & \multicolumn{2}{c|}{4} \\
\hline $\begin{array}{l}\text { in bet vervolg zal } \\
\text { in Zukunft wird }\end{array}$ & $\begin{array}{l}\text { bij } u \\
\text { er Sie }\end{array}$ & $\begin{array}{l}\text { altijd } \\
\text { immer }\end{array}$ & $\begin{array}{l}\text { naar buis brengen } \\
\text { nach Hause bringen }\end{array}$ & $\begin{array}{l}\text { na bet werk } \\
\text { nacb der Arbeit }\end{array}$ \\
\hline
\end{tabular}


Diese Einteilung, die zwar fürs Niederländische entworfen wurde, aber unserer Meinung nach auch fürs Deutsche verwendet werden kann, bietet u.a. den Vorteil, daß die klammerbildenden Elemente auch in das Schema aufgenommen sind. Bei dieser Beschreibung wird, wie schon klar geworden sein mag, nicht von der Funktion der Satzglieder ausgegangen, sondern von ihren Stellungseigenschaften.

Für jedes der 5 Stellungsfelder wollen wir untersuchen, welche Ähnlichkeiten und/oder Unterschiede zwischen dem Niederländischen und dem Deutschen bestehen. Die angeführten Beispiele wurden zum großen Teil H. Mulisch, De diamant (Amsterdam 1966 ${ }^{2}$ ) und seiner deutschen Übersetzung durch B. Loets: Der Diamant (Hamburg 1961) - abgekürzt HM - und G. Grass, Katz und Maus (rororo 572, Reinbek bei Hamburg 1963) und seiner niederländischen Úbersetzung durch $\mathrm{H}$. Manger: Kat en Muis (Amsterdam 1969 ${ }^{3}$ ) - abgekürzt GG - entnommen; wo es uns interessant schien, benutzten wir aber auch andere Quellen oder bildeten selbst Beispielsätze.

Bevor die einzelnen Stellungsfelder behandelt werden, müssen aber noch ein paar Anmerkungen gemacht werden.

\subsubsection{Anmerkungen}

0.2.2.1. Bis jetzt wurde vom Formhauptsatz ausgegangen; das dafür entworfene Schema gilt aber auch, leicht abgeändert (vor allem im 1. und 4. Stellungsfeld), für die anderen Satztypen. Wir geben hier kurz einige an:

- In einem Wunschsatz enthält das erste Stellungsfeld normalerweise nur ein Element: das finite Verb

Kwam bij tocb maar!

Käme er docb!

- Das gilt auch für Entscheidungsfragen und imperativische Befehlssätze:

Kom je morgen?

Kommst du morgen?

Kom morgen bij mij

Komm morgen zu mir

Hier kann aber ein Konditionalsatz vor das finite Verb treten (für das Deutsche vgl. Kufner, 1963, S. 5 und 14 - 15): 
Wenn du Lust bast, komm mit

Als je lust bebt, kom mee

Wenn du Zeit bast, kommst du dann?

Als je tijd bebt, kom je dan?

Im Gegensatz zum Niederländischen können (müssen? vgl. Vindevogel 1966, S. 83) im Deutschen auch bestimmte Modaladverbien vor dem Imperativ stehen:

Wacht nu eens even (HM 106)

Nun warte mal

Nach Flämig können auch andere Elemente "aus Gründen des Anschlusses oder der Hervorhebung" (1964, S. 324) dem Imperativ vorangehen:

Auf ibn verlaß dich lieber nicbt

Ein weiteres Beispiel dafür fanden wir bei S. Lenz:

"Gut", sagte der Chef, "dann gib es ber. Und die anderen Papiere gib mir morgen." (Der Mann im Strom, dtv 102, München $1970^{6}$, S. 42)

- Auch ein Konditionalsatz kann in der Form eines Stirnsatzes auftreten:

Mocht bij komen, zeg bem dan dat ik dadelijk bier ben

Sollte er kommen, sage ibm, ich seigleich bier

- In einem Formnebensatz steht das finite Verb hinten im Satz, neben den infiniten Verbteilen. Sie bilden den einen Teil der Klammer, den anderen bildet die Subjunktion (die subjunktionale Gruppe), die dann das einzige Element des ersten Stellungsfeldes ist:

dat bij morgen zal komen

daß er morgen kommen wird

(zeg me,) met wie je komt

(sag mir,) mit wem du kommst

Vom zweiten Stellungsfeld an gelten für die nichtverbalen Elemente im Satz aber dieselben Stellungsregeln, ungeachtet des Satztyps.

0.2.2.2. Auch sind nicht immer alle 5 Stellungsfelder besetzt; in:

bij komt niet

er kommt nicht 
sind die Felder 2, 3 und 5 leer: bij komt/er kommt bilden das 1. Feld, das 3. enthält niet/nicht.

0.2.2.3. Außer Betracht lassen wir das Stück, das Paardekooper "aanloop" nennt: die man/den Mann in:

die man, die ken ik

den Mann, den kenne ich nicht

Ein solches Stück kann ohne weiteres weggelassen werden, ohne daß die Struktur des Satzes geändert wird (es wird wieder aufgenommen durch die/den), und es kommt außerdem relativ selten vor.

0.2.2.4. Nicht behandelt werden weiter auch die Konjunktionen (en/ und, maar/über ...): sie stehen zwischen den Sätzen, die sie verbinden, und sind deshalb für die Untersuchungen zur Wortstellung nicht wichtig.

\section{Das erste Stellungsfeld}

1.1. Im ersten Stellungsfeld stehen, wenigstens im Formhauptsatz (für die anderen Satztypen siehe 0.2.2.1.), normalerweise nur 2 Elemente, und zwar:

1. das finite Verb

2. ein anderes Stück

natürlich in umgekehrter Abfolge. Wenn das Subjekt vor dem finiten Verb steht, spricht man von gerader Stellung, wenn ein anderes Element an die Spitze des Satzes tritt, von ungerader Stellung oder Inversion.

1.2. Auffallend ist, daß sogar im prozentualen Vorkommen von Sätzen mit Inversion zwischen dem Deutschen und dem Niederländischen eine relativ große Ubereinstimmung besteht, wenigstens in literarischer Prosa: Niederiändisch: 40\% (Nieuwborg, 1968), 36\% (Bauwens, 1964); Deutsch: 37,4\% (De Smet, 1970), 37,5\% (Sommerfeldt, 1966); es bestehen hier aber ziemlich große individuelle Unterschiede:

A. Van der Leeuw: 54,2\%, P. Van Aken: 28,6\% (Bauwens, 1964, S. 9);

A. von Chamisso: $17,8 \%$, Th. Mann 39,4\% (Winter, 1961, S. 200). In 
nichtliterarischer Prosa scheint Inversion häufiger vorzukommen, jedenfalls im Deutschen: in wissenschaftlicher Prosa: 46,7\% (De Smet, 1970), 41,1\% (Winter, 1961); in Zeitungen: 55,4\% (De Smet, 1970), zwischen 34,5\% und 43\% (Winter, 1961), 39,3\% (Sommerfeldt, 1966, der noch Unterschiede fand nach den verschiedenen Sachgebieten: Politik: 29,3\%, Wirtschaft: $44,3 \%$, Sport: $41,5 \%$ ). Fürs Niederländische verfügen wir hier nicht über vergleichbares Material.

1.3. Wichtiger als die Frequenz dieser Erscheinung ist die Frage, was bei Inversion vor das finite Verb tritt (treten kann). Fast alles kann im ersten Stellungsfeld stehen.

1.3.1. Es gibt aber Elemente, die nur im ersten Stellungsfeld auftreten können.

1.3.1.1. Die fragenden Wörter (Wortgruppen mit fragendem Element), die Relativpronomina und -adverbien und die Subjunktionen (subjunktionalen Gruppen):

In welchem Jabr lief der Kreuzer "Eritrea" vom Stapel?...

Wieviel Knoten läuft er? (GG 46)

In welk jaar liep de kruiser "Eritrea" van stapel?...

Hoeveel knopen loopt bij?

(nur jenes Minensucbboot der Czaika-Klasse,) das ibm später erste Auftrittsmöglichkeiten bot (GG 27)

(alleen die mijnenveger van de Tsaike-klasse,) die bem later zijn cerste kansen bood om op te treden.

(und ich bewunderte Dich,) obne daß Du es darauf angelegt battest (GG 25)

(en ik bewonderde je) zonder dat bet bet daarop bad aangelegd.

1.3.1.2. Weiter auch einige satzverknüpfende Adverbien wie so/so:

und so lasse ich am Anfang die Maus über den Schraubenzieber büpfen (GG 6)

en zo laat ik in bet begin de muis over de schroevedraaier hippen

Fürs Niederländische vgl. Koelmans (1970, S. 26).

1.3.1.3. Im Deutschen kommt hier auch noch das expletive es hinzu:

es bätten an Stelle der Hostien auch Türbeschläge, Werkzeuge oder wie einst, Turngeräte, Schlaghölzer und Stafettenstäbe verteilt werden können (GG 70) 
Im Niederländischen dagegen kommt neben

Maar er kwam een woedende storm, die de windstreken door elkaar wierp (HM 14)

auch noch vor:

Plotseling was er ook geren in de tuinkamer en weer lawaai, nu van brekend bout (HM 50)

1.3.1.4. Aus dem Vorhergehenden geht hervor, daß die in 1.3.1.2. und 1.3.1.3. erwähnten Elemente nicht in einem Formnebensatz vorkommen können, weil das erste Stellungsfeld dort nur die Subjunktion enthält (vgl. 0.2.2.1.).

1.3.2. Andererseits sind auch einige Elemente von der Spitzenstellung im Satz ausgeschlossen, u.a. die unbetonten deklinierten Formen des Personalpronomens und des Reflexivpronomen.

Fürs Niederländische vgl. Paardekooper (1968, S. 153 - 154):

* ze beb ik nooit meer gezien

*'t kan ik beter maken

Eine Ausnahme bildet hier aber die feste Fügung:

me dunkt dat ...

Fürs Deutsche siehe Engel (1970a, S. 79):

*ibm babe ich ibn gezeigt

*ibn babe ich ibm gezeigt

Auch einige Modaladverbien wie eens('s)/mal können nicht die erste Stelle im Satz einnehmen; vgl. Engel (1970a, S. 73 ff.), Rijpma - Schuringa $(1969$, S. 174 und 227):

Das soll mir mal einer nacbmacben (GG 24)

Dat moet iemand me's nadoen

Auf die Unmöglichkeit, im Niederländischen einen mit zodat eingeleiteten Konsekutivsatz an die Spitze des Satzes zu stellen, hat Nieuwborg hingewiesen (1968, S. 11):

"Zodat we niet vertrokken, regende bet

Fürs Deutsche siehe Leys, 1971, S. 33, Anmerkung 23, der neben den so daß-Sätzen: 
*so daß er nun ruben mußte, batte er sebr schwer gearbeitet auch noch die als daß-Sätze erwähnt:

*als daß er dies hätte kaufen können, war er zu arm

Hinzugefügt werden könnten, fürs Niederländische und fürs Deutsche, auch noch die Vergleichssätze:

* dan ik dacht is bij ouder

*als ich dachte, ist er älter

1.3.3. Einige Elemente wie niet/nicht können nur unter bestimmten Bedingungen vor dem finiten Verb stehen: "Der Gegensatz, an dem niet teilhat, muß auch noch einen anderen Teil des Satzes umfassen, der - vorzugsweise auch durch Umfang und Stellung - stark opponieren muß" (Koelmans, 1970, S. 23). Wie De Schutter mit Recht behauptet (1967, S. 51 - 52), kann das opponierende Element nur im 5. Stellungsfeld stehen:

Niet beboren bij bovengenoemde namen de Vlaamse plaatsnamen Coxyde (...), Raversijde: zij zijn ... (A. Van Loey, Schönfelds historische grammatica van het Nederlands, S. 32, zitiert nach Koelmans, 1970, S. 21)

Fürs Deutsche vgl. Erben (1967, S. 158):

Nicht mag das Eigne prunkend wie Fremdes sein (R.A. Schröder, Oden 6)

1.4. Das Element vor dem finiten Verb kann rein satzverknüpfend sein: ein Beispiel dafür gaben wir schon in 1.3.1. Es kann aber auch etwas Neues bringen, das gleichsam den Ausgangspunkt bildet für das was folgt, das das Folgende situiert:

(Ondanks bet bezit van de Siddharta ging het met de macht der Kandvoepta-dynastie gestadig bergafwaarts.) Staatkundig bleek er plotseling geen rol meer voor haar te zijn (HM 30) Politisch gab es mit einmal offenbar keine Aufgabe mebr für sie

Am wichrigsten für uns sind aber die Fälle, in denen ein Element durch Voranstellung stark hervorgehoben wird. Das ist meistens so bei infiniten Verbformen und bei notwendigen Verbergänzungen: 
aanvaarden zult $u$ bet (HM 91)

annebmen werdet ibr es

Groß war die polnische Flotte nicbt, aber ebrgeizig (GG 27)

Groot was de poolse vloot niet, maar eeruchtig

1.4.1. Besondere Aufmerksamkeit verdient die Spitzenstellung des direkten (und in geringerem Maße des indirekten) Objekts. Diese unterliegt bestimmten Bedingungen, im Niederländischen mehr als im Deutschen (vgl. Van Haeringen, 1956, S. 88).

\subsubsection{Ein Satz wie:}

Aber den meisten Beifall stapelte Mablke wäbrend der Sommerferien auf dem abgesoffenen Kabn (GG 23)

Maar bet meeste succes oogstte Mablke in de zomervakantie op de verzopen schuit

ist sowohl im Deutschen als auch im Niederländischen unzweideutig. Denn ein Abstraktum wie Erfolg/succes kann nicht als Subjekt von stapeln/oogsten verwendet werden, auf keinen Fall, wenn als direktes Objekt eine Personenbezeichnung vorkommt. (Stilmittel wie die Metapher werden hier außer Betracht gelassen.) Dies ist, was Erben (1967, S. 40) nach Leisi "semantische Kongruenz" nennt. Einen wichtigen Versuch, die semantische Kongruenz zu formalisieren, findet man in: G. Helbig, W. Schenkel, Wörterbuch zur Valenz und Distribution deutscher Verben. Im Deutschen kommt noch die "formale Kongruenz" hinzu, in dem hier angeführten Beispiel durch die Deklinationsendungen des Artikels und des Adjektivs. Aber auch wenn die Funktion nicht an solchen formalen Merkmalen ersichtlich ist, können Sätze wie:

Das Amulett an Mablkes Hals beanstandete Mallenbrandt nie (GG 11)

\section{Gebübr bezablt Empfänger}

durch die semantische Kongruenz nicht falsch verstanden werden.

1.4.1.2. Anders ist es aber, wenn die semantische Kongruenz als Unterscheidungsmittel nicht genügt, wie in:

Aucb Robert Kennedys Witwe fand kein Kameramann in Tränen

(Der Spiegel, 17.6.1968, zitiert nach De Smet, 1970, S. 66) 
Dieser Satz kann nur dank der formalen Kongruenz richtig interpretiert werden. Da das Niederländische fast keine Deklinationsendungen mehr hat, ist eine solche Konstruktion im Niederländischen nicht mög* lich. In:

Ook Robert Kennedy's weduwe vond geen cameraman in tranen würde, wenn der Kontext keine genauen anderen Hinweise enthält, $R o$ bert Kennedy's weduwe als Subjekt aufgefaßt werden.

1.4.1.3. Wenn weder die semantische und die formale Kongruenz noch der Kontext weiterhelfen, wird auch im Deutschen das Element in Spitzenstellung als Subjekt betrachtet:

Die Mutter siebt die Tochter

Peter gab Karl das Bucb

In einem solchen Fall spricht man von "grammatisch bedingter Gliedfolge" (siehe Flämig, 1964, S. 334).

\subsubsection{Der Verbzusatz}

\subsubsection{Hier sind nicht Fälle gemeint wie:}

doch voort schrijdt de keizer, stram van lichaam en geest (HM 89) doch weiter schreitet der Kaiser - straff an Leib und Geist

Voortschrijden und weiterscbreiten sind mehr als Zusammenfügungen denn als echte Zusammensetzungen zu betrachten, und die Elemente voort/weiter können in gewissem Sinne noch als vorangestellte Lokaladverbien interpretiert werden. Dies gilt auch noch für weiter rückten, nicht aber für auf stiegen im folgenden Beispiel:

und weiter rückten die Karren, und Körbe senkten sicb durcb Scbäcbte binab, und Karren neigten sich über die Körbe, und auf stiegen die Körbe und scbwenkten sich über verrückende Züge (P. Weiß, Abschied von den Eltern, edition suhrkamp, $1969^{5}$, S. 23)

Weitere Beispiele für diesen zweiten Typ gibt T. Auerbach (1960, S. 16): Auf atmete Jebeid (Feuchtwanger) anklagt dicb die Menscbbeit vorm Gericht (Becher)

Solche Konstruktionen, bei denen nach E. Riesel "durch die Nichttrennung des trennbaren Verbs stilistische Anfangsstellung des Prädikats mit 
emphatischem Klang eintritt" (1962, S. 280), treten auch (aus Gründen der Kostenersparung?) oft in Telegrammen auf:

mitteilt sofort

annebmen Angebot

Diese Nichttrennung scheint uns im Niederländischen kaum möglich zu sein. Die von Koelmans angeführten Beispiele (1970, S. 26):

(ik kom niks tekort boor, maar over bou ik ook niets over bebben we vijf schoenen en zes spijkers (N.R.C., 13.10.1965,S. 3) over blijft een verscheurd mens (5 minuten V.P.R.O., 7.55-8,19. Nov. 1968, Besprechung eines Schauspiels)

gehören mehr zu denen des Typs voort scbrijdt. Ein Argument bietet uns hier auch die deutsche Ubersetzung der betreffenden Verben: over wird hier nicht mit über sondern mit übrig übersetzt, das mit dem Verb auch eher eine Zusammenfügung als eine Zusammensetzung bildet und deswegen auch vorangestellt werden kann. Von den anderen Beispielen, die er selbst konstruiert hat:

(je kunt je wel verzetten, maar) tegen bou je dat niet

(die dingen zien er wel onooglijk uit, maar) stuk gaan ze niet gauw, gibt er auch zu, daß sie wohl einigermaßen gewagt sind. (Vgl, stukgaan überdies mit voortscbrijden.)

Vollkommen unmöglich scheint:

"tegen kom je zoiets niet meer

Nach De Schutter spielt hier der Grad der semantischen Unabhängigkeit des Verbzusatzes eine entscheidende Rolle.

1.4.2.3. Die einzige Verbindung, die sowohl im Niederländischen als auch im Deutschen normal genannt werden kann, ist:

vast staat dat ... fest steht, daß...

Im übrigen sind wir der Meinung, daß ähnliche Konstruktionen bei zusammengesetzten Verbformen in der Gegenwartssprache vollkommen unmöglich sind:

*auf ist ein Mann gefallen

"over is een verscbeurd mens gebleven 


\subsection{Das expletive er/es}

1.5.1. In 1.3.1. haben wir schon auf einen ersten Unterschied zwischen dem Deutschen und dem Niederländischen im Hinblick auf die Verwendung des expletiven er/es hingewiesen. Hier wollen wir noch auf einen zweiten näher eingehen. Er betrifft zwar weniger die Stellungsmöglichkeiten als vielmehr die Verwendungsmöglichkeiten dieses Elements, scheint uns aber doch in den Rahmen dieser Untersuchung zu passen.

Sowohl im Deutschen als auch im Niederländischen kann das expletive er/es vor dem finiten Verb stehen, wenn das Subjekt unbestimmt (und zählbar) ist (Beispiel siehe 1.3.1.3.). Das ist im Deutschen aber auch möglich, wenn das Subjekt bestimmt ist:

Es ärgerten uns die Scbüler der Untertertia und Obertertia (GG 54) We ergerden ons aan de jongens van de lagere klassen

Wie aus der Übersetzung hervorgeht, sind die Verwendungsmöglichkeiten des expletiven Elements im Niederländischen in dieser Hinsicht beschränkter als im Deutschen. Doch kann das niederländische er auch bei einem bestimmten Subjekt vorkommen, aber nur:

- bei bestimmten Verben, wie zijn, bestaan:

Er zijn dezulken die scheeldenken (HM 22)

Er bestaat bij sommigen de neiging om alleen die woorden en uitdrukkingen als $A B N$ te erkennen die voorkomen in de gewone omgangstaal van beschaafd sprekende Noordnederlanders of eigenlijk alleen maar in de beschaafde taal van Westelijk Nederland (J.L. Pauwels, Winkler Prins Woordenboek met encyclopedische informatie, Amsterdam - Brussel, 1959, S. 14).

Weitere Beispiele (alle mit zijn) werden noch angeführt bei Nieuwborg (1968, S. 80 und 149).

- wenn er nicht nur expletiv ist, sondern auch erster Teil eines getrennten Pronominaladverbs (vgl. Bech, 1952, S. 25):

$n u$ is er dit van geworden

1.6. Anmerkungen

1.6.1. Normalerweise steht vor dem finiten Verb im Formhauptsatz nur 1 Element. Es gibt aber auch Abweichungen von dieser Regel. 
1.6.1.1. Vor oder nach diesem Element kann ein Adverb vorkommen wie ook/auch, ecbter/jedoch:

Ook dit waren nauwelijks gedacbten te noemen (HM 130)

Doch auch das konnte man kaum Gedanken nennen

De paleispriester echter stond inmiddels te bibberen als een terdoodveroordeelde (HM 18)

Der Palastpriester jedoch stand derweile dabei und zitterte wie ein zum Tode Verurteilter

Solche Adverbien, deren Zahl beschränkt ist (fürs Deutsche vgl. Engel, 1970a, S. 79 - 80), können auch als Attribute zu dem Element, dem sie vorangehen oder folgen, betrachtet werden (Engel nennt sie QuasiAttribute) und bilden also nur eine scheinbare Abweichung von der oben formulierten Regel.

\subsubsection{Anders ist es mit Sätzen wie:}

Von dort aus, von jener Minute an liefen wir durch unbelebte Vorortstraßen (GG 122)

Van deze plek vandaan, sinds die minuut, liepen wij door levenloze voorstadstraten

Sie sind vielleicht einigermaßen ungewöhnlich, aber man kann sie doch nicht ohne weiteres für ungrammatisch halten. Die vorangestellten Adverbialien situieren lokal und temporal, was im Folgenden ausgedrückt wird, und können auf diese Weise als einigermaßen zusammenhängend angesehen werden. Ob hier aber alle möglichen Kombinationen von Adverbialien vorkommen können, müßte näher untersucht werden.

\subsubsection{Als ungrammatisch gelten meistens Konstruktionen wie:}

En de oude man, terwijl bij extatisch alles begon te verstaan, voelde krachten in zich rondtasten, die zelfs keizers konden doen dromen (HM 89),

die an den Periodenbau des klassischen Latein erinnern (vgl. Merckens, 1960, S. 248). Daß in der Ubersetzung eine Änderung vorgenommen wurde:

Und wäbrend der alte Kaufmann in Extase begriff, füblte er Kräfte in sich erwachen, die selbst Kaiser träumen macben könnten, weist darauf hin, daß auch im Deutschen ähnliche Konstruktionen als weniger normal aufgefaßt werden (vgl. Grebe, 1966, S. 644). 
1.6.1.4. Wenn eine infinite Verbform vorangestellt wird, kann sie von Verbergänzungen begleitet werden:

dit boek naar de stad meenemen zal ie wel niet (Paardekooper, 1955, S. 16)

Recbt laut scbreien müßt ibr (Engel, 1970a, S. 80)

Die infiniten Verbformen bilden hier mit ihren Ergänzungen eine semantische Einheit. Sätze wie:

Mit den Hübnern ins Bett gehen sie dort

Ausdrücklich auf dieses Faktum bat nur D. Jones bingewiesen

(E. Coseriu, Einführung in die strukturelle Linguistik. Autori-

sierte Nachschrift besorgt von G. Narr und R. Windisch, Tübingen, S. 15)

in denen neben einer notwendigen Verbergänzung noch ein weiteres Element vorangestellt ist, werden von Engel (1970a, S. 80 - 81) als grammatisch betrachtet. Im Niederländischen scheinen uns derartige Konstruktionen unmöglich.

1.6.2. In der Alltagssprache kommen öfters Aussagesätze vor, die gleich mit dem finiten Verb anfangen (vgl. Engel, 1970a, S. 88 - 89):

Kann icb noch nicbt sagen

Auch in der geschriebenen Sprache gibt es einen derartigen Typ von Aussagesätzen, den "Beteuerungssatz" mit dem Adverbiale doch:

(Dennoch überragt er alle berkömmlichen Darstellungen der Negation), sind docb die dort entwickelten syntaktiscben und semantiscben Kriterien für eine einbeitlicbe Interpretation negativer Sätze nocb wesentlich unzureichender (K.H. Stahl, in: Wissenschaftlicher Literaturanzeiger 10 (1971), Februar, S. 12)

\section{Das zweite Stellungsfeld}

Aus Gründen der Úbersichtlichkeit scheint es uns gut, hier die Sätze ohne Inversion einzeln zu behandeln. 


\subsection{Sätze ohne Inversion}

2.1.1. Unmittelbar nach dem finiten Verb stehen, im Niederländischen und im Deutschen, die Personalpronomina, Reflexivpronomina und Demonstrativpronomina, soweit sie nicht stark betont sind.

aber sie ließen mich nicht (GG 5)

maar ze lieten me niet gaan

Hij bad zich voorgenomen rijk te worden (HM 11)

Er batte sich vorgenommen reich zu werden

De mensheid, waarvan bij zich de dienaar achtte, mocbt dit misschien niet begrijpen (HM 41)

Die Menscbheit, für deren Diener er sich bielt, begriff das vielleicbt nicbt.

Im Niederländischen kommt noch er hinzu. Dieses er kann sein:

- expletiv (vgl. 1.5.):

Gisteren waren er veel toeristen in de stad

- lokal:

Hij was er graag

- partitiv:

Daar zaten er toen wel viff

- es kann auch der erste Teil eines getrennten Pronominaladverbs sein:

Hij had er toch aan gedacht

\subsubsection{Die Folgeregeln im zweiten Stellungsfeld}

Hier weichen das Deutsche und das Niederländische voneinander ab.

2.1.2.1. Fürs Niederländische wurde dieses Teilgebiet der Wortstellung untersucht von B. Van den Berg. Er kommt zu der folgenden Stellungsregel, die gilt, ungeachtet der Funktion der Pronomina: ' $t$ - Reflexivpronomina - andere Personalpronomina als ${ }^{~} t$ - Demonstrativpronomina (1967, S. 311):

Hij berinnerde 't zich niet

$\mathrm{Hij}$ zei bet ons niet

Ik stelde me dat zo voor

Ik had je dit al eerder willen vragen 
Er als erster Teil eines getrennten Pronominaladverbs steht nach bet:

Hij baalde bet er vlug uit,

hat den anderen Personalpronomina und dem Reflexivpronomen gegenüber aber keine feste Stellung: es kann ihnen sowohl vorangehen als auch folgen:

Hij vermaakte er zich wel mee

Hij vermaakte zich er wel mee

Hij vermaakte er $u$ wel mee

Hij vermaakte $u$ er wel mee

Es scheint jedoch eine Tendenz zu bestehen, er voranzustellen (vgl. Van de Velde, 1967, S. 134: $18 \mathrm{mal}$ er-Pronomen, 0 mal Pronomen - er)

Dieselbe Tendenz scheint zu bestehen. wenn er lokal oder partitiv ist:

Hij beeft er ons ontmoet

Hij heeft er bem twee gegeven

Die Abfolge Pronomen - er scheint uns auch möglich zu sein, vor allem bei schwach betonten Pronomina (vgl. 2.1.2.1.2.):

Hij beeft je er ontmoet

Hij heeft er je ontmoet

Hij heeft je er twee gegeven

$H i j$ beeft er je twee gegeven

Wenn er als erster Teil eines getrennten Pronominaladverbs oder als partitives Attribut aber zugleich expletiv ist, folgt es immer unmitteibar dem finiten Verb:

Toen zijn er bem beelwat mensen komen opzoeken

Toch badden er bem slechts twee mee gelukgewenst

Diese allgemeine Regel kann im großen und ganzen genügen, sie bedarf aber noch einiger Ergänzungen.

2.1.2.1.1. Dieselben Stellungseigenschaften wie het scheint uns ze zu haben. Die Abfolge:

Ik geef je ze

die Paardekooper (1955, S. 84) neben:

ik geef ze je 
angibt, klingt uns weniger vertraut. $Z e$ scheint, wie bet, vor die anderen Pronomina zu treten.

${ }^{*} H i j$ kon zich ze zo voorstellen

2.1.2.1.1. Wenn zwei andere Personalpronomina als bet/ze nebeneinander vorkommen, scheinen uns zwei Abfolgen möglich, je nach der Betonung der Pronomina.

Als Übersetzung von:

Welcher Fiscb bringt ibn mir (GG 136)

könnte statt:

Welke vis brengt bem mij

auch:

Welke vis brengt mij (me) bem

gestanden haben. Das am wenigsten betonte geht voran (vgl. De Schutter, 1970, S. 163). Diese Freiheit in der Stellung ist dadurch zu erklären, daß einige Personalpronomina im Niederländischen auch in der Schriftsprache neben einer vollen Form eine schwache Form haben und also die Betonung auch angegeben werden kann. Es muß aber hinzugefügt werden, daß ein solches Aufeinanderfolgen von Personalpronomina meistens vermieden wird, indem das indirekte Objekt in der Form einer Präpositionalgruppe auftritt:

Mablke wollte ibn mir geben (GG 129)

wird im Niederländischen:

Mablke wilde hem aan mij geven

Es besteht keine Freiheit in der Abfolge, wenn eines von den Pronomina die Funktion eines Genitivobjekts hat: dieses folgt im Niederländischen, wie übrigens im Deutschen, den anderen Pronomina:

O Volmaakte, entferm u mijner (HM 28)

o Vollkommener, erbarme dich meiner

2.1.2.1.3. Paardekooper weist noch auf die Möglichkeit hin, 't in einem Befehlssatz der betonten Form eines Personalpronomens folgen zu las$\operatorname{sen}(1955$, S. 95):

geef mij 't maar 
2.1.2.2. Im Deutschen folgt, genauso wie im Niederländischen, das Demonstrativpronomen den anderen Pronomina:

ich erlaube mir das

ich erlaube dir das

Bei den Personal- und Reflexivpronomina bestimmt die Funktion die Stellung: das direkte Objekt geht dem indirekten Objekt voran:

Mablke machte es sich nicht leicht (GG 128)

Scbiller und ich sprangen von der Barriere, fingen die Mädcben auf und stellten sie ibm vor (GG 41)

2.1.2.2.1. Die einzige Abweichung von dieser Regel ist die vor allem in der Umgangssprache vorkommende Nachstellung der enklitischen Form 's (Engel, 1970a, S. 59):

ich babe dem's nicht gesagt

ich babe euch's gelebrt

2.2. Den Formhauptsätzen mit Inversion schließen sich auch die anderen Satztypen (Entscheidungsfrage, Formnebensatz) an. Wie wir schon in 0.2 .2 .1 . erwähnten, fallen alle Typen, was die Stellung der nichtverbalen Elemente betrifft, vom 2. Stellungsfeld an zusammen.

\subsubsection{Das Subjekt ist ein Personalpronomen oder $m e n / m a n$}

Das Subjekt folgt dem finiten Verb oder der Subjunktion immer unmittelbar.

want met modder wast men zich bet schoonst (HM 11)

denn mit Schlamm wäscht man sich am schönsten

maar als bij haar bijna beeft bereikt (HM 15)

doch als er sie beinabe erreicht bat

2.2.1.1. Nur eine scheinbare Abweichung von dieser Regel bildet ein Fall wie:

Nu schreeuwde ook bij (HM 76)

Da scbrie auch er,

der zu vergleichen ist mit den in 1.6.1.1. behandelten Konstruktionen.

2.2.1.2. Wenn dem Subjekt mehr als ein Pronomen folgt, gilt für diese Pronomina die Abfolge, wie sie in 2.1.2. beschrieben wurde: 
jetzt zeige ich es Euch bald von der anderen Seite (HM 76)

$\mathrm{Nu}$ laat ik bet jullie gauw van de andere kant zien

\subsubsection{Das Subjekt ist ein Demonstrativpronomen}

Im Niederländischen bestimmt die Funktion meistens die Abfolge: das Subjekt geht den anderen Pronomina voraus:

dat deze bem in bet bezit bad gesteld van de eeuwig - allergrootste diamant - die genaamd zou zijn: de Siddharta (HM 26)

Im Deutschen dagegen scheint die Funktion nicht die Stellung des Demonstrativpronomens den anderen Pronomina gegenüber zu bestimmen: das Demonstrativpronomen folgt:

weil sicb das anbot (GG 7)

Zudem gebt dich das wirklich nichts an, Mama (GG 96)

Die Stellung des Demonstrativpronomens ist aber nicht so fest: in beiden Sprachen kann auch die umgekehrte Abfolge vorkommen (fürs Niederländische vgl. Van den Berg, S. $307-308$ ). Dies geht hervor aus Sätzen wie:

indien bem dat goeddacbt (HM 25)

und:

aber schon drängte dieser ibn zur Seite als Übersetzung von:

maar reeds duwde de betreffende bem opzij (HM 31)

Im Niederländischen scheint diese zweite Stellungsmöglichkeit sich jedoch auf die Formen dit/dat zu beschränken:

*indien bem deze vroeg

2.2.3. Als allgemeine Anmerkung zu den Folgeregeln für die Pronomina gilt noch, daß zwischen den Pronomina normalerweise kein anderes Element steht. Sätze wie:

daß Sie daber sich mit allen Kräften bemüben werden, sie gut auszufüllen (F. Kafka, Das Schloß, 1958, S. 94)

toen bij op een weekse avond baar bezocht (F. Bordewijk, Karakter, naar Van de Velde, 1967, S. 135 - 136)

sind denn auch als ungewöhnlich zu betrachten. 
2.2.4. Das Subjekt ist eine Nominalgruppe

Aus Beispielen wie:

Zudem bätte uns die Hafenpolizei oder die Marine ausgehoben (GG 57)

Bovendien zou de bavenpolitie of de marine ons opgepikt bebben

Bis zum beutigen Tag bat mir Musik keinen größeren Genuß verschaffen können (GG 62)

Nog altijd beeft muziek mij geen groter genot verschaft

könnte geschlossen werden, daß im Niederländischen die Abfolge Subjekt - Pronomina gilt, im Deutschen dagegen die Abfolge Pronomina Subjekt. Dies ist zwar in vielen Fällen so, als allgemeine Regel kann diese Abfolge aber nicht gelten.

2.2.4.1. Im Niederländischen ist die Lage nicht sehr klar, und die Meinungen gehen, was das hier behandelte Problem betrifft, auseinander. Es scheint auf jeden Fall notwendig, zwischen den verschiedenen Arten von Pronomina zu unterscheiden.

2.2.4.1.1. Neben der Nominalgruppe als Subjekt kommt ein Personalpronomen vor

Nach Nieuwborg(1968, S. 113 u.a.) ist die Abfolge Pronomen - Subjekt fast immer möglich. Nur bet als Teil einer festen Verbalfügung bildet hier eine Ausnahme (S. 120):

dan beeft Suzanne bet bij bet rechte eind (I. Van Goeree)

* dan beeft bet Suzanne bij bet recbte eind

Diese sehr allgemeine Regel ermöglicht es ihm, eine Abfolge wie:

Waarom misleiden ons de grote goden zelfs met ... (P. Lebeau)

die zwar in bestimmten Mundarten geläufig ist, den meisten Niederländischsprachigen aber fremd vorkommen wird (vgl. Mars, 1970, S. 34), noch als gewöhnlich zu betrachten.

Während er in:

Vaak overviel haar de gewaarwording dat de tijd was teruggedraaid (H. Haasse)

die Nachstellung des Subjekts dadurch erklärt, daß Verb und Subjekt eine abstrakte Bedeutungsgruppe bilden, die im emotionalen Bereich 
liegt, sind wir geneigt, die Länge des Subjekts als entscheidenden Faktor zu betrachten.

Die Tendenz, das Pronomen dem Subjekt vorangehen zu lassen, scheint wohl stärker zu sein bei einem unbestimmten Subjekt als bei einem bestimmten (vgl. Nieuwborg, 1968, S. 219):

Toen besprong haar een radeloze angst

Toen besprong die radeloze angst baar

Häufig kommt sie vor bei der Kopula:

bet mooist lijken mij de groene kopjes

Bei einer Passivkonstruktion ist die Nachstellung des Pronomens sogar unmöglich:

gisteren werd mij een eigenaardige geschiedenis verteld, ebenso wie in einem Satz mit einem expletiven er:

nooit bad er een man baar aangeraakt (Vestdijk, nach Nieuwborg, 1968, S. 216)

scheint uns kaum grammatisch zu sein; normal wäre hier:

nooit bad er baar een man aangeraakt

2.2.4.1.2. Ein Reflexivpronomen und eine Nominalgruppe als Subjekt Auch hier besteht nach Nieuwborg eine große Freiheit in der Stellung. Das Reflexivpronomen kann stets vor dem Subjekt stehen. Diese Abfolge kommt aber weniger vor, wenn der Transitivitätsgrad zwischen Verb und Reflexivpronomen größer wird (1968, S. 224):

Over de weg bewogen zich enkele kinderen

Telkens als de fotograaf afdrukte bewogen enkele kinderen zich

Nach De Schutter (1970, S. 159) kann die Abfolge Reflexivpronomen Subjekt nur vorkommen bei reflexiven Verbindungen, die bedeuten: te voorschijn komen, beginnen:

Toen vormde zich een grote menigte

Toen vertoonden zich de eerste symptomen

In diesen Fällen ist Voranstellung des Subjekts nicht möglich.

Scheint letztere Regel uns ein wenig zu streng, so trifft erstere unserer Meinung nach auch nicht ganz zu. Weitere Untersuchungen werden eine 
Erklärung dafür bringen müssen, warum

naar de deur, waar zich thans een beer in enigszins versleten rok opbield (HM 165)

noch als normal betrachtet werden kann,

Toen ook de bloemen, die uit haar banden waren gewaaid, baar langzaam badden gevolgd, sloot zich de kloof met een eenvoudig gebaar der aarde (HM 131)

dagegen schon weniger grammatisch scheint.

2.2.4.1.3. Ein Demonstrativpronomen und eine Nominalgruppe als Subjekt

Normalerweise wird im Niederländischen das Subjekt dem Demonstrativpronomen vorangestellt:

Heeft mijn broer dat niet verteld?

Die Nachstellung des Subjekts scheint uns kaum unmöglich. Nieuwborgs Beispiel (1968, S. 154):

Alle kinderen moeten op banden en voeten voortkruipen:

eerst doen dat de jongens, dan de meisjes.

ist jedenfalls zweifelhaft.

2.2.4.1.4. Fassen wir zusammen: im Niederländischen ist die Abfolge Nominalgruppe als Subjekt - Pronomen die normale, die Umkehrung dieser Abfolge bleibt auf bestimmte Fälle beschränkt.

\subsection{Anmerkung}

Im Niederländischen gehört auch noch er zum zweiten Stellungsfeld (vgl. 2.1.1.). Wenn das expletive er im 2. Stellungsfeld vorkommt, steht es an erster Stelle, also auch vor einer Nominalgruppe als Subjekt:

vanmorgen is er een student naar $u$ komen vragen

Das ist auch der Fall, wenn das expletive er mit er als Teil eines getrennten Pronominaladverbs oder als partitivem Attribut zusammenfällt:

toch beeft er toen een deskundige op gewezen

toch beeft er gisteren een jongen twee gekregen 
Wenn er nur erster Teil eines getrennten Pronominaladverbs oder partitives Attribut ist, steht es normalerweise nach dem Subjekt:

toen beeft de voorzitter er wel op gewezen toen beeft mijn broer er twee gekregen

Es kann aber auch dem Subjekt vorangehen (vgl. J.L. Pauwels, 1959, S. 64):

toen beeft er de voorzitter wel op gewezen

toen beeft er mijn broer twee gekregen

Diese Abfolge wird aber von einigen als weniger grammatisch betrachtet (vgl. Mars, 1970, S. 35).

Das lokale er steht meistens vor dem Subjekt:

gisteren beeft mijn vriend er nog een interessant boek gevonden, obwohl gelegentlich auch die umgekehrte Abfolge vorkommt:

Afgezien van bet beschaafd dat in de kerk, op school en bij officiele gelegenbeden wel degelijk gesproken wordt, kan er de jongere generatie een als beschaafd Nederlands bedoelde taalvorm banteren die boven bet dialect staat (J. Goossens in: De nieuwe taalgids, Van Haeringennummer, 1970, S. 65)

Sie scheint vor allem möglich, wenn im Satz auch noch ein Pronomen steht:

Een paar ogenblikken tevoren bad er zich dat verscbrikkelijk ongeval voorgedaan

2.2.4.2. Im Deutschen scheinen die Folgeregeln einfacher zu sein.

2.2.4.2.1. Ein Personalpronomen und eine Nominalgruppe als Subjekt Die normale Abfolge ist: Personalpronomen - Subjekt:

bis mich unser L I durch die Sprecbanlage zurickrief (GG 66)

Manchmal steht das Pronomen auch nach dem Subjekt:

Sobald wir fertig waren und ebe meine Cousinen den Mund aufmacben konnten, schickte Mablke uns weg (GG 43 - 44),

aber auch hier bleibt die Normalfolge möglich.

Nur in den Fällen, in denen die Wortstellung das einzige Mittel ist, die Funktion anzugeben, muß das Subjekt vorangehen (vgl. 1.4.1.): 
(Da kam Anna angelaufen.) Gleich hatte Gisela (Nom.) sie (Akk.) geseben

Gleich batte sie (Nom.) Gisela (Akk.) geseben

Solche Fälle scheinen uns aber relativ selten vorzukommen. Meistens werden hier wohl andere Mittel gesucht, die mögliche Doppeldeutigkeit zu vermeiden.

2.2.4.2.2. Auch das Reflexivpronomen geht gewöhnlich dem Subjekt voran:

Daß sich Mablke zunickbielt (GG 51)

Wie beim Personalpronomen kommt auch hier die umgekehrte Abfolge vor:

Aucb bätten die beiden Dinger sich nie mit einem Typ einigen lassen, der... (GG 42)

Notwendig ist die Voranstellung des Subjekts aber nie.

2.2.4.2.3. Im Deutschen steht manchmal auch das Demonstrativpronomen vor der Nominalgruppe als Subjekt:

Doch batte dies schon der herzoglich schwäbische Rudolf von Ems in seinem "Willebalm"-Roman getan, in dessen Richtung sich Berthold zu bewegen scheint (F. Neumann, Geschichte der altdeutschen Literatur 800 - 1600, S. 200, nach De Smet, 1970, S. 234).

Normaler scheint uns wohl die Voranstellung des Subjekts, wie in der Ubersetzung von:

En toen Jaflet dit zag (HM 69)

Und als Jaflet das sab

2.2.4.2.4. Die allgemeine Regel scheint im Deutschen wohl zu sein, daß Personalpronomina und Reflexivpronomina der Nominalgruppe als Subjekt vorangehen, Demonstrativpronomina ihr dagegen folgen. Es besteht aber die Möglichkeit, auch die Personal- und Reflexivpronomina folgen zu lassen. De Smet fand in seinem Material:

$$
\text { vor dem Subjekt nach dem Subjekt }
$$

Personalpronomina

Reflexivpronomina 
Das steht wohl im Gegensatz zu den Behauptungen Grebes, es bestehe in der Gegenwartssprache eine starke Neigung, die Pronomen, die in der Rolle eines Objekts stehen, aus der ihnen zukommenden Stellung [d.h. gleich nach dem finiten Verb] zu verdrängen (1966, S. 640).

\subsection{Auf die Tatsache, daß das expletive es nur im 1. Stellungs-} feld auftreten kann, wiesen wir schon in 1.5.2.2. hin.

\subsubsection{Wenn neben einer Nominalgruppe als Subjekt mehr als 1 Pro-} nomen auftritt, folgen diese Pronomina den Stellungsregeln, wie sie oben beschrieben wurden, sowohl was die Stellung gegenüber dem Subjekt (vgl. 2.2.4.1. und 2.2.4.2.), als auch was die Stellung untereinander (vgl. 2.1.2.) betrifft. Dies gilt nicht nur fürs Deutsche, sondern auch fürs Niederländische:

Und dann zeigte Mablke es uns (GG 9)

En toen liet Mablke bet ons zien

Dabei boten sich ibm, der ein Jabr älter war, die besten Chancen, vor uns rauszukommen (GG 78)

2.2.4.4. Es muß schließlich noch hinzugefügt werden, daß, wenn ein oder mehrere Pronomina der Nominalgruppe als Subjekt folgen, zwischen diesen Elementen normalerweise kein anderes Satzglied steht. Ungewöhnlich sind Sätze wie:

En eens dat Steven, toen ik van zo'n tocbt terugkwam, me vroeg waar ik been was geweest $(\mathrm{H}$. Teirlinck, Zelfportret of het Galgemaal, S. 70 nach Van de Velde, 1967, S. 136) so werden einst die Würmer aucb in euren fleischernen Stötzchen sich erlustigen (E. Mörike, nach O. Behaghel, 1932, S. 69)

die im Deutschen eher vorzukommen scheinen als im Niederländischen, vor allem bei einem Reflexivpronomen. Von Polenz fragt sich deshalb, "ob hier nicht gerade das Reflexivum auf dem Weg ist, immer mehr den "telischen" Gliedern der engeren Sphäre des Verbs sich anzuschließen und damit einen ähnlichen Wortstellungsrang wie die Satzverneinung sich zu erobern" (1966, S. 10 - 11).

In dem deutschen Beispiel fällt noch eine zweite "Unregelmäßigkeit" auf, nämlich daß ein Element vor dem Subjekt steht, wenn diesem Subjekt noch ein Pronomen folgt. Auch im Niederländischen werden im Gegensatz zu dem, was der Bearbeiter der Grammatik von Rijpma - 
Schuringa behauptet, Sätze wie:

Later kon meestal mijn vader 't zich niet meer berinneren (1969, S. 237)

omdat later mijn vader 't zich niet meer kon berinneren (1969,

S. 228)

allgemein als ungrammatisch betrachtet.

Wenn das Subjekt folgt, braucht es aber nicht gleich den Pronomina zu folgen, wie schon aus Beispielen in 2.2.4.2.3. (dies schon der berzoglich schwäbische Rudolf von Ems) und in 2.2.4.1.1. (mij wel de groene kopjes) hervorgeht.

\subsection{Zusammenfassung}

Das 2. Stellungsfeld wird im Deutschen und im Niederländischen nach hinten von den Pronomina abgeschlossen. Im Niederländischen gehört dazu meistens auch die Nominalgruppe als Subjekt, weil sie in der Regel den Pronomina vorangeht (vorangehen muß); im Deutschen ist dies auch möglich, notwendig aber fast nie.

\subsection{Anmerkung}

In 2.1.1. wurden die Pronomina ohne Attribute behandelt. Wird ein Pronomen aber verstärkt durch Elemente wie alleen/allein, nur, zelf/selbst, dann stehen sie im 3. Stellungsfeld (fürs Niederländische vgl. Van Es, 1970, S. $32-33$ ):

\section{Vielleicht hatte wirklich nur sie eine (GG 36)}

Misscbien bad inderdaad alleen zij er eentje

de man beklaagde baar, beklaagde met een gebaar zichzelf en zucbtte om bet leven (HM 145)

der Mann beklagte sie, beklagte mit einer Gebärde sich selbst und seufzte, ja das Leben.

Selten kommt ein Pronomen ohne solches Attribut im 3. Stellungsfeld vor; das ist nur möglich, wenn es stark betont ist, wie in:

ich schwimme langsam in der Brustlage, sebe weg zu vorbei, zwischen Resten der Entlüfter bindurch - wieviel waren es eigentlich? - sebe, bevor meine Hände den Rost fassen, Dich, seit gut fünfzehn Jabren : Dich! schwimme, fasse den Rost, sebe Dich (GG 81) 
Es ist aber nicht immer leicht zu entscheiden, wie stark ein Pronomen eigentlich betont ist.

\section{Das dritte Stellungsfeld}

Dieses Stellungsfeld kann nur mit Hilfe der anderen Stellungsfelder abgegrenzt werden: es ist der Teil des Satzes, der zwischen dem zweiten und dem vierten Stellungsfeld steht. Bemerkenswert ist für diesen Teil auch die relativ große Stellungsfreiheit der zugehörigen Elemente. Neben:

bij beeft dat boek gisteren gekocht er bat das Buch gestern gekauft

kann auch vorkommen:

bij beeft gisteren dat boek gekocht er bat gestern das Bucb gekauft

Die Stellung der Elemente ist hier jedoch nicht vollkommen willkürlich. Sie ist bestimmten Regeln unterworfen, die fürs Deutsche konkret ausgearbeitet wurden von Engel (1970, S. 43 - 72). Fürs Niederländische gibt es u.a. die Detailuntersuchung von Nieuwborg (1968) über die Stellung des Subjekts und des direkten Objekts; auf einige Faktoren, die auf die Wortstellung Einfluß haben können, wiesen wir selbst hin (1967, S. 144 - 156). Eine vollständige Übersicht zu geben, ist eine unmögliche Aufgabe. Deshalb wollen wir uns hier darauf beschränken, die wichtigsten Faktoren anzudeuten, die die Wortstellung im 3. Stellungsfeld bestimmen; dabei stützen wir uns vor allem auf die Übersicht von Flämig (1964, S. $334-343)$.

\subsection{Die Funktion bestimmt die Abfolge}

Die grammatisch bedingte Gliedfolge, die wir schon in 1.4.1.3. besprachen, gilt auch für Sätze mit Inversion. Auch im 3. Stellungsfeld geht das Subjekt normalerweise dem direkten Objekt voraus.

Daarop vroeg de kolonel Mme Boechowa ten buwelijk (HM 147) Darauf bat der Oberst Mme Buchowa um ibre Hand

Während semantische oder formale Kongruenz oder der Kontext die Voranstellung des direkten Objekts zuließen, ist die Abfolge direktes 
Objekt - Subjekt im 3. Stellungsfeld nur sehr beschränkt möglich (vgl. 3.3.):

\author{
*gestern bat ein Fabrrad Karl gekauft \\ "gisteren beeft een fiets Karl gekocht \\ *gestern bat den Fremden Karl ausgelacht \\ ${ }^{*}$ gisteren beeft de vreemdeling (Akk.) Karl (Nom.) uitgelachen
}

\title{
3.2. Die syntaktische Bindung ans Verb bestimmt die Abfolge
}

Das mit dem Verb am engsten verbundene Element steht möglichst weit hinten im 3. Stellungsfeld. Auf diese Weise ist, wenigstens im Deutschen, die Abfolge indirektes Objekt - direktes Objekt, wenn beide durch eine Nominalgruppe ausgedrückt sind, zu erklären.

Karl bat seinem Bruder ein Buch gekauft Im Niederländischen scheinen aber kompliziertere Verhältnisse vorzuliegen. Wenn beide Objekte durch eine Nominalgruppe ausgedrückt sind, gilt hier dieselbe Folgeregel wie im Deutschen:

Karl beeft zijn broer een boek gekocht

Das indirekte Objekt kann aber auch in der Form einer Präpositionalgruppe vorkommen, und dann ist neben der Stellung:

Karl beeft aan zijn broer een boek gegeven die Folgevariante:

Karl beeft een boek aan zijn broer gegeven möglich, ohne daß eine Änderung in der syntaktischen Bindung ans Verb auftritt.

\subsection{Der Mitteilungswert bestimmt die Abfolge}

Diese Auffassung, nach der im 3. Stellungsfeld die Stellung der Elemente von links nach rechts mit ihrem steigenden Mitteilungswert übereinstimmt, wird vor allem von der Prager Schule vertreten (u.a. von Beneš). Fürs Niederländische hat Nieuwborg die Bedeutung der "semantischen Stratifikation" betont.

Diese dritte Regel kann mit den beiden vorhergehenden zusammenfallen; daß sie aber wichtiger ist als diese, geht daraus hervor, daß sie, wenn die grammatisch-syntaktische Funktion und der Mitteilungswert 
nicht übereinstimmen, die anderen Regeln aufheben kann.

3.3.1. Wenn das indirekte Objekt in der Form einer Nominalgruppe wichtiger ist als das direkte Objekt in der Form einer Nominalgruppe, kann letzteres im Deutschen vorangehen:

er werde die ärgerliche Geschichte dem Direktor der Schule übergeben (GG 74)

Das indirekte Objekt wird auf diese Weise stark hervorgehoben.

Das Niederländische kennt diese Abfolge nicht, wenn beide Objekte durch eine Nominalgruppe ausgedrückt sind; es verfügt hier aber über eine andere Möglichkeit (vgl. 3.2.), bei der allerdings das indirekte Objekt durch Nachstellung nicht stark betont ist.

3.3.2. Im Niederländischen und im Deutschen folgt das Subjekt zuweilen dem direkten Objekt:

Ook bereikten Jaflet toen berichten over muiterij en desertie (HM 69)

So erreichte die Lausitz ein Zustrom der Nosvicer Kultur aus Böbmen (zitiert nach Beneš, 1968a, S. 68)

Solche Konstruktionen kommen aber relativ selten vor; sie scheinen auch näher zu bestimmenden Bedingungen zu unterliegen. Meistens werden sie vermieden, vor allem wenn Doppeldeutigkeit entstehen könnte:

In diesen Stunden (innerbalb eines Praktikums) unterrichten die Kinder (Akk.) die Studenten (Nom.), (sonst immer die Lebrer) (zitiert nach Neumann, 1968, S. 60)

\section{Das vierte Stellungsfeld}

In diesem Stellungsfeld werden ein verbaler und ein nichtverbaler Teil unterschieden.

\subsection{Der nichtverbale Teil des vierten Stellungsfeldes}

In 3.2. bemerkten wir schon, daß die syntaktische Bindung ans Verb einen Einfluß hat auf die Stellung der Satzglieder. Einige nun sind so eng mit dem Verb verbunden, daß sie, soweit sie nicht vorangestellt 
sind (vgl. 1.4.), mit dem verbalen Teil des 4. Stellungsfeldes eine untrennbare Einheit bilden, d.h. daß zwischen dem nichtverbalen und dem verbalen Teil kein fremdes Element stehen kann. Daß es nicht leicht ist zu bestimmen, was genau zu diesem nichtverbalen Teil gehört, geht schon aus der uneinheitlichen Behandlung dieses Problems in der Fachliteratur hervor.

Fürs Niederländische umschreibt Paardekooper diesen Teil z.B. in seiner "Beknopte ABN-syntaksis" (1968, S. 157 - 159) schon anders als in "Syntaxis Spraakkunst en Taalkunde" (1955, S. 110 - 111), und auch im Deutschen besteht keine Einstimmigkeit über dessen Abgrenzung. Selbst wenn man - im Gegensatz zu Ostendorp (1958, S. 142) fürs Niederländische und Engel (1970, S. 81) fürs Deutsche noch als weiteres Abgrenzungskriterium annimmt: "In Verbindung mit einem Infinitiv oder mit einem Partizip II kann eine "primäre" Verbergänzung nie der verbalen Form folgen, von der sie abhängt" (De Schutter, 1967, S. 48), so daß möglich sind: Hij is niet ziek geweest/Er ist nicht krank gewesen, Ziek is bij niet geweest/Krank ist er nicht gewesen und Ziek geweest is hij niet/Krank gewesen ist er nicht, nicht aber: Geweest is bij niet ziek/Gewesen ist er nicht krank und Hij is niet geweest ziek/Er ist nicbt gewesen krank, kommt man nicht sehr viel weiter. Trotz der Fragen, die hier noch offen bleiben, glauben wir, zum nichtverbalen Teil des 4 . Stellungsfeldes rechnen zu können:

- ein Adjektiv als Prädikativ oder als notwendige Artergänzung:

bij is nog altijd ziek er ist noch immer krank

bij verfde de muur geel er strich die Wand gelb

- eine notwendige Raumergänzung zu einem Zustandsverb (ausgenommen die "Pronomina" bier/bier, er, daar/da, dort):

bij woont al lang in Berlijn

er wobnt schon lange in Berlin

- eine notwendige Richtungsergänzung zu einem nicht zusammengesetzten Verb, das eine Ortsveränderung ausdrückt (ausgenommen "Pronomina" wie daarbeen/dortbin): 
bij rijdt volgende week naar Zwitserland

er fäbrt näcbste Woche in die Scbweiz

- eine Nominalgruppe oder eine Präpositionalgruppe als Teil einer festen Verbalfügung:

bij neemt op de bank plaats er nimmt auf der Bank Platz

men nam de machine in gebruik man nabm die Maschine in Gebraucb

Im Niederländischen kommen noch hinzu:

- der zweite Teil eines getrennten Pronominaladverbs:

bij beeft er mij tenslotte toch van overtuigd

- die "Postposition" einer "Postpositionalgruppe":

bij is bet buis toen snel in gelopen

Im Deutschen:

- eine Nominalgruppe als Prädikativ:

er ist doch Bürgermeister geworden

4.2. Bei der Behandlung des verbalen Teils des 4. Stellungsfeldes gehen wir von der Stellung im Formnebensatz aus, denn in diesem Satztyp stehen alle Verbalformen im 4. Stellungsfeld, und von der Stellung im Formnebensatz kann die im Formhauptsatz leicht abgeleitet werden: das finite Verb rückt ins 1 . Stellungsfeld. Vollständigkeit kann hier nicht angestrebt werden. Wir beschränken uns darauf, Verbalgruppen zu beschreiben, die in beiden Sprachen vorkommen. Die Behandlung einer Gruppe wie: toen bij stond te kijken wird hier also als irrelevant beiseite gelassen, weil sie keine Entsprechung im Deutschen hat und deshalb nur wichtig ist bei der Untersuchung der niederländischen Verbalgruppen. Weiter beschreiben wir nur die zwei- und dreigliedrigen Gruppen: größere kommen relativ selten vor; Näheres darüber ist zu finden bei Schulz-Griesbach (1970, S. 409 - 413), Jorgensen (1964, S. 162 171), Engel (1970a, S. 35 - 37), De Schutter (1964, S. $67-84)$ und J.L. Pauwels (1965, S. $105-110$ und 1970, S. 93 - 97), auf die wir uns hier auch stützen. Auch auf die Unterschiede zwischen geschriebener und gesprochener Sprache gehen wir nicht ein; fürs Ndl. vgl. A. Pauwels (1953), J. Stroop (1970), V.F. Vanacker (1970b). 


\subsubsection{Eine zweigliedrige Verbalgruppe}

\subsubsection{Ein finites Verb und ein Partizip II oder ein reiner Infinitiv}

4.2.1.1.1. Im Niederländischen ist die Voranstellung des finiten Verbs stets möglich: "links bestimmt also rechts" (eigentlich: der Inhalt von links bestimmt den von rechts):

dat bij is gekomen

dat bij werd gezocht

dat bij zal komen

dat bij bem laat komen

In vielen Fällen kann jedoch auch das finite Verb nachgestellt werden; diese Abfolge kommt in dem Material von De Schutter (1964, S. 68 ff.) sogar in $56,6 \%$ der Fälle vor in der Verbindung finites Verb - Partizip II:

dat bij gekomen is

dat bij gezocht werd

Bei den modalen Hilfsverben ist diese Abfolge weniger geläufig (16,9\%):

dat bij komen zal

Bei den meisten anderen Verben, die mit einem reinen Infinitiv verbunden werden, (und auf jeden Fall bei komen, leren und belpen) ist Nachstellung des finiten Verbs unmöglich:

dat bij bem kwam balen

dat bij (bem) leert zwemmen

Ein Satz wie:

de meest oppassende zoon die zich denken liet (Bordewijk, zitiert nach De Schutter, 1964, S. 75)

scheint uns ziemlich ungewöhnlich zu sein. Overdiep (1949, S. 530) hält die Nachstellung von laten sogar für unmöglich.

4.2.1.1.2. Im Deutschen ist die Abfolge hier fest: das finite Verb steht hinten: rechts bestimmt links

daß er gekommen ist

daß er gesucht wird

daß er kommen wird

daß er ibn kommen laßt 
4.2.1.2. Ein finites Verb und ein te/zu-Infinitiv

4.2.1.2.1. Die Stellung ist im Niederländischen bei den meisten Verbindungen relativ fest: das finite Verb geht voran:

dat bij bet scbeen te weten

dat bij probeerde te lachen

dat bij begon te wenen

dat bij bet niet boefde te weten

Die umgekehrte Abfolge findet man auch bei der Verbindung zijn, blijven oder bebben + te-Infinitiv (vgl. De Schutter, 1964, S. 78, Sassen, 1963, S. 20). Sie ist sogar geläufiger:

dat die vrucbten niet te eten zijn dat die vrucbten niet zijn te eten

Die von Mulisch verwendete Konstruktion:

toen er iets in de gebavende zoldering te bewegen aanving ( $\mathrm{HM} 25$ ) klingt aber sehr ungewöhnlich. Einfluß des Deutschen scheint hier nicht ausgeschlossen zu sein.

4.2.1.2.2. Das Deutsche hat normalerweise Nachstellung des finiten Verbs:

daß er es zu wissen schien

daß er zu lachen versuchte

daß er zu weinen anfing

daß er es nicht zu wissen braucbte

Bei einigen Verben kann der $z u$-Infinitiv aber auch folgen:

daß er anfing zu weinen

4.2.1.2.3. Wenn Ergänzungen den te/zu-Infinitiv begleiten, kann die ganze Infinitivgruppe, jedenfalls wenn sie länger wird, bei bestimmten Verben (u.a. tracbten/versucben) nachgestellt werden. Vergleiche:

dat bij met zijn buren vrede probeerde te sluiten daß er mit seinen Nacbbarn Frieden zu scbließen versucbte mit:

dat bij probeerde met zijn buren vrede te sluiten daß er versucbte, mit seinen Nacbbarn Frieden zu scbließen 
Der $t e / z u$-Infinitiv steht dann aber mit seinen Ergänzungen im 5. Stellungsfeld, so daß wir es mit einer anderen Satzstruktur zu tun haben: statt einer zweigliedrigen Verbalgruppe tritt eine Verbindung von einem finiten Verb mit einem abhängigen Infinitivsatz auf. Ähnliches kommt vor bei Verben wie belpen/helfen und leren/lebren, lemen, wenn diese statt mit einem reinen Infinitiv mit einer $t e / z u$-Infinitivgruppe verbunden werden (vgl. De Schutter, 1964, S. 65 und Grebe, 1966, S. 528 - 529 und 546 - 547). Vergleiche:

dat bij mij bielp zoeken daß er mir suchen balf

mit:

dat bij mij hielp bet zware werk tot een goed einde te brengen daß er mir half, die scbwere Arbeit zu einem guten Ende zu bringen

Es muß hier aber noch hinzugefügt werden, daß im Deutschen (längere) Infinitivgruppen häufiger innerhalb des Satzrahmens stehen. So kann z.B. eine $z u$-Infinitivgruppe in einem Nebensatz dem Adjektiv (als Prädikativ oder als notwendiger Artergänzung), von dem sie abhängt, vorangehen:

wer in ibrer Mitte saß und den zäben Kucben des dritten Kriegsjabres mit der Gabel manierlicb zu verringern bemübt war (GG 75),

was im Niederländischen unmöglich ist. Einige weitere Beispiele:

soweit also der Text des Scblagers, der offenbar nicht anders als all die andern ist, sondern für viele zu steben beansprucben kann (R.F. Antoch, in: Akzente 1971, H.3, S. 284)

und aucb diese nützen nicht, wenn man nicbt wenigstens das Große Latinum und das Kleine Graecum binter sich gebracht und in einem balbend Dutzend soziologischer und psychologischer Universitätsseminare sich zu tummeln Gelegenbeit batte (S. Dörffeldt, in: Muttersprache 81 (1971), S. 77)

\subsubsection{Eine dreigliedrige Verbalgruppe}

4.2.2.1. Die erste Ergänzung zum finiten Verb ist ein reiner Infinitiv oder ein Partizip II

4.2.2.1.1. Als allgemeine Regel kann fürs Niederländische angenommen werden, daß die Abfolge "links bestimmt rechts" in den meisten Fällen 
möglich ist. Sie kommt fast immer vor, wenn dem finiten Verb zwei reine Infinitive folgen (von denen der erste ein Ersatzinfinitiv sein kann):

dat bij zal moeten komen dat bij niet was willen komen

J.L. Pauwels erwähnt aber auch Fälle wie:

die zijn doodvonnis boren uitspreken bad voor bij een antwoord kunnen bedenken bad

Da diese Konstruktion nur bei den westflämischen Schriftstellern A. Demedts und S. Streuvels aufgezeichnet wurde, könnte hier Einfluß der Mundart bestehen; es muß aber festgestellt werden, daß diese Abfolge auch in anderen Mundarten normal ist (J.L. Pauwels, 1965, S. 109 und 1970, S. 93).

Wenn der zweite Infinitiv ein te-Infinitiv ist, bestimmt die Art der Verbindung von reinem Infinitiv und $t e-$ Infinitiv die Abfolge (vgl. 4.2.1.2.1.)

Hängt der $t e$-Infinitiv direkt von einem Verb ab, das in einer zweigliedrigen Gruppe vorangeht (dat bij probeert te komen), so ist auch hier nur die Abfolge "rechts bestimmt links" möglich:

dat bij zal proberen te komen,

auch wenn der reine Infinitiv ein Ersatzinfinitiv ist:

dat bij was proberen te komen

Wenn der $t e$-Infinitiv aber von einem Verb abhängt, das in einer zweigliedrigen Verbalgruppe normalerweise folgt (dat bet te doen is), so kann das finite Verb vorangehen oder zwischen den beiden Infinitiven stehen:

dat bet zal te doen zijn dat bet te doen zal zijn

Erstere Abfolge kommt nach J.L. Pauwels (1970, S. 94) mehr im Nordniederländischen vor, letztere mehr im Südniederländischen. Die Abfolge "links bestimmt rechts" ist hier aber unmöglich.

4.2.2.1.1. Wenn mit dem finiten Verb ein Infinitiv Perfekt oder ein Infinitiv Passiv verbunden ist, kommen neben der Abfolge "links bestimmt rechts": 
dat bij zal zijn gekomen

auch noch andere vor (vgl. De Schutter, 1969, S. 81 und J.L. Pauwels, 1965, S. 107 und 1970, S. 94 - 95): die mehr nordniederländische:

dat bij gekomen zal zijn

und die mehr südniederländische:

dat bij zal gekomen zijn

Selten kommen nach J.L. Pauwels auch noch Konstruktionen vor wie:

bet lied dat gezongen worden zal (Streuvels)

Im Nordniederländischen scheint sogar noch ein Unterschied zu bestehen zwischen verschiedenen Stilgattungen. Im Gegensatz zur literarischen Prosa, die meistens hat:

dat bijgekomen zal zijn

bevorzugt die Zeitungssprache (J.L. Pauwels, 1970, S. 95):

dat bij zal zijn gekomen

Fürs Südniederländische gibt es hier keine vergleichenden Untersuchungen.

4.2.2.1.1.2. Unmöglich ist die Abfolge "links bestimmt rechts", wenn das finite Verb mit zwei Partizipien II verbunden ist. In diesem Fall sind möglich

dat bij is gezocht geweest dat bij gezocht is geweest

dat bij gezocbt geweest is (geringerer Grammatikalitätsgrad)

4.2.2.1.2. Im Deutschen gilt wieder die allgemeine Regel "rechts bestimmt links":

daß es getan werden soll

daß er gekommen sein soll

daß er gesucbt worden ist

daß er steben bleiben soll

Die Abweichungen von dieser Regel sind relativ leicht zu formulieren.

4.2.2.1.2.1. Das finite Verb muß vorangehen (beeinflußt dabei aber nicht die Abfolge der anderen Elemente), wenn die Gruppe einen Ersatzinfinitiv enthält: 
daß er bat kommen müssen

daß er ibn bat kommen seben

oder wenn dem finiten Verb zwei Infinitive folgen, von denen einer modal ist (vgl. Engel, 1970a, S. 37, Jorgensen, 1964, S. 166 - 167):

daß er wird kommen können

Dies gilt auch, wenn das finite Verb modal ist:

daß er soll kommen können

4.2.2.1.2.2. Wenn das finite Verb eine Form des temporalen werden oder eines Modalverbs ist, kann es aber auch vorangehen, wenn es mit zwei nichtmodalen Infinitiven verbunden ist:

daß er ibn wird kommen seben

daß er ibn kommen seben wird

daß er uns kann singen bören

daß er uns singen bören kann

Normalerweise wird aber die finite Verbform eines Modalverbs nicht vorangestellt (vgl. Jфrgensen, 1964, S. 167).

4.2.2.1.2.3. Das finite Verb steht sehr selten voran, wenn ein Infinitiv Perfekt oder ein Infinitiv Passiv folgt (vgl. J $\phi$ rgensen, S. 165):

daß er konnte gekommen sein

daß er es konnte getan baben

4.2.2.1.2.4. In der Grammatik von Schulz-Griesbach (1970, S. 411) wird die doppelte Stellungsmöglichkeit des finiten Verbs noch mehr beschränkt: sie wird nur zugelassen, wenn das temporale werden mit zwei Infinitiven verbunden ist, von denen der erste ein Infinitiv Passiv ist:

daß das Buch von ibm wird liegen gelassen werden daß das Bucb von ibm liegen gelassen werden wird

4.2.2.1.2.5. Wenn der zweite Infinitiv ein $z u$-Infinitiv ist, sind nach Jørgensen (1964, S. 168 - 169) auch nebeneinander möglich:

daß er etwas zu tun baben sollte

daß er etwas sollte $z$ tun baben 
Wird brauchen aber in einer zusammengesetzten Vergangenheitsform mit einem Infinitiv verbunden, so muß das finite Verb voranstehen, denn braucben bildet seine zusammengesetzten Vergangenheitsformen mit einem Ersatzinfinitiv (vgl. 4.2.2.1.2.1.):

daß er nicht batte zu kommen brauchen

\subsubsection{Die erste Ergänzung zu dem finiten Verb ist ein $t e / z u$-Infinitiv}

4.2.2.2.1. Wenn die zweite Ergänzung ein Partizip II ist (d.h. bei einem Infinitiv Passiv oder Perfekt), bestehen im Niederländischen neben der Abfolge "rechts bestimmt links":

dat bij alles meende te bebben gezien

auch noch zwei weitere Möglichkeiten (vgl. 4.2.2.1.1.1.):

dat bij alles gezien meende te bebben

dat bij alles meende gezien te bebben

Wenn die zweite Ergänzung aber ein reiner Infinitiv ist, dann bestimmt links stets rechts:

dat bij alles meende te kunnen oplossen

4.2.2.2. Im Deutschen ist die Abfolge "rechts bestimmt links" bei einem Infinitiv Passiv oder Perfekt die gebräuchlichste:

daß er gekommen zu sein schien daß es getan zu werden braucbt

Relativ selten wird das finite Verb hier vorangestellt (Jథrgensen, 1964, S. 165):

daß er scbien gekommen zu sein

daß es braucht getan zu werden

Wenn der zweite Infinitiv ein reiner Infinitiv ist, besteht eine doppelte Stellungsmöglichkeit:

daß er nicht kommen zu können schien

daß er nicht schien kommen zu können

\subsubsection{Zusammenfassung}

Im Niederländischen ist, mit wenigen Ausnahmen, die Abfolge "links bestimmt rechts" möglich, in vielen Fällen besteht aber eine große 
Freiheit in der Stellung. Im Deutschen dagegen gilt allgemein die Folgeregel "rechts bestimmt links". Auch hier gibt es einige Ausnahmen; die Stellungsfreiheit ist jedoch viel beschränkter.

\subsubsection{Die Stellung des Verbzusatzes}

4.2.4.1. Im Niederländischen kann der Verbzusatz von dem Hauptverbsimplex getrennt werden und vor die ganze Verbalgruppe gestellt werden:

terwijl bij baar aan bleef zien (HM 21)

In seinem Material fand W. De Cubber, der diese Erscheinung untersuchte, Trennung des Verbzusatzes in etwa $10 \%$ der möglichen Fälle $(1968$, S. 103 ff.). Die Frequenz ist aber unterschiedlich je nach der Art des Verbzusatzes (Adverb, Adjektiv) und der Art der Verbalgruppe (vgl. auch J.L. Pauwels, 1970, S. 97 - 100). Die getrennte Stellung kommt häufiger bei Nordniederländern (13\%) vor als bei Südniederländern (7\%), obwohl auch hier große individuelle Unterschiede bestehen (Bomans trennt in dem von De Cubber untersuchten Material kein einziges Mal, I. Michiels $15 \mathrm{mal}$ ), die vielleicht auf Stilunterschiede zurückzuführen sind: Trennung des Verbzusatzes scheint eher bei den Schriftstellern vorzukommen, die sich mehr nach der gesprochenen Sprache richten.

4.2.4.2. Im Deutschen besteht diese Möglichkeit der Trennung nicht: der Verbzusatz ist im 4. Stellungsfeld fest mit dem Hauptverbimplex verbunden. Es scheint im Gegenteil eine gewisse Tendenz zu bestehen, trennbar zusammengesetzte Verben als untrennbar zusammengesetzt zu behandeln. Ein typischer Fall ist anerkennen. Weitere Beispiele, vor allem von mit an zusammengesetzten Verben, gibt Möller (1965, S. 96): anberaumen, anempfeblen, anerzieben, anvertrauen. Auf die Vorliebe expressionstischer Schriftsteller für solche Konstruktionen weist Auerbach (1960, S. 16) hin (vgl. 1.4.2.2.):

Aber den Beitrag der Zeit auslöscht stets Gerechtigkeit (Becher) 


\subsection{Durchbrechung im 4. Stellungsfeld}

4.3.1. Ein Element zwischen dem nichtverbalen und dem verbalen Teil des 4 . Stellungsfeldes

4.3.1.1. Zwischen einem Adjektiv als Prädikativ oder als notwendiger Artergänzung und dem verbalen Teil des 4. Stellungsfeldes kann z.B. eine Präpositionalgruppe stehen:

bij is tevreden over u geweest er ist zufrieden mit Ibnen gewesen

Von echter Durchbrechung des 4 . Stellungsfeldes kann hier aber nicht die Rede sein; Adjektiv und Präpositionalgruppe können als ein Ganzes betrachtet werden, wenn auch Kern und Attribut dieser Gruppe untereinander keine feste Stellung aufweisen:

bij is over $u$ tevreden geweest er ist mit Ibnen zufrieden gewesen

bij is tevreden geweest over $u$ er ist zufrieden gewesen mit Ibnen

\subsubsection{Auch die Negation kann zwischen dem nichtverbalen und} dem verbalen Teil des 4 . Stellungsfeldes vorkommen, z.B. bei einem durch $z o /$ so bestimmten prädikativen Adjektiv:

bij is zo dom niet geweest, dat te geloven er ist so dumm nicht gewesen, das zu glauben

oder auch bei einer Nominalgruppe als Prädikativ, die wir im Deutschen auch zum nichtverbalen Teil des 4 . Stellungsfeldes rechnen:

$d a \beta d u$ der erste nicht bist, der das sagt

Besonders im letzten Fall kann die Negation nicht ohne weiteres als Attribut zum nichtverbalen Teil des 4 . Stellungsfeldes betrachtet werden. Weitere Untersuchungen können vielleicht dazu führen, auch nicht (und alles, was nach dem satzverneinenden nicht auftritt) zum 4. Stellungsfeld zu rechnen, wie dies u.a. Boost (1964, S. 47 - 49) tut.

\subsubsection{Durchbrechung des verbalen Teils des 4. Stellungsfeldes}

\subsubsection{Bisweilen steht im Niederländischen auch ein nichtverbales} Element zwischen den Verbformen. Es gehört meistens zum nichtver- 
balen Teil des 4. Stellungsfeldes und ist auf jeden Fall syntaktisch eng mit dem Verb verbunden. Uber diese Erscheinung, besonders in literarischer Prosa, siehe Van de Velde, 1969, wo auch auf weitere Literatur verwiesen wird. Zusammenfassend kann gesagt werden, daß diese Konstruktion, die mehr im Südniederländischen vorkommt als im Nordniederländischen und deshalb von einigen als fehlerhaft betrachtet wird, auch im Südniederländischen bei weitem nicht allgemein ist (sie kommt in dem untersuchten Material in 22,9\% der möglichen Fälle vor). Sie tritt auch mehr in der Mundart auf als in der Schriftsprache, vor allem in südniederländischen Mundarten (vgl. Vanacker, 1964 und 1970a) und war im 17. Jahrhundert noch allgemein verbreitet, auch im Nordniederländischen (vgl. Koelmans, 1965, S. 159 - 160).

4.3.2.2. Auch im Deutschen können Ergänzungen, die syntaktisch eng mit dem Verb zusammenhängen, zwischen die Verbformen gestellt werden. Dies ist aber nur möglich, wenn das finite Verb mit zwei reinen Infinitiven verbunden ist (Schulz-Griesbach, 1970, S. 410):

und nachdem icb in der Abteilungsküche batte Kleinbolz macben müssen (GG 108)

Eine andere Abfolge wäre hier eher ungewöhnlich.

Diese Durchbrechung kam früher auch im Deutschen öfter vor, wie aus einem Satz hervorgeht, der aus einer in archaisierendem Deutsch verfaßten Bibelübersetzung stammt:

so wirst du ibn finden, wenn $d u$ ibn wirst von ganzem Herzen und von ganzer Seele sucben

(Die Bibel nach der deutschen Übersetzung D. Martin Luthers (Stuttgart, 1937), zitiert nach Koelmans, 1965, S. 165)

Vgl. auch Mattausch (1965, S. 89 - 94).

\section{Das fünfte Stellungsfeld}

5.1. Nicht immer schließt das 4. Stellungsfeld den Satz ab. Nach dem nichtverbalen oder verbalen Teil des 4 . Stellungsfeldes kann noch etwas stehen; aber sehr selten ist diese Stellung notwendig (vgl. 1.3.2.). 
5.1.1. Möglich ist sie nur bei den Elementen, die keine feste Stellung in einem anderen Stellungsfeld haben. Ausgeschlossen von der Stellung im 5. Stellungsfeld sind also die in 1.3.1. behandelten Elemente, die unbetonten Pronomina (vgl. 2.2.), einige Modaladverbien (vgl. 1.3.2.) und die nichtverbalen Teile des 4. Stellungsfeldes (vgl. 4.1.).

5.1.2. Normal ist die "Ausklammerung", wenn das betreffende Element relativ lang ist, vor allem wenn das 4 . Stellungsfeld dagegen kurz ist, z.B. wenn es nur aus dem Verbzusatz besteht (vgl. Rath, 1965, S. $222 \mathrm{ff}$.). Auf diese Weise wird vermieden, daß das Element des 4. Stellungsfeldes "nachklappt". Das kann der Fall sein

- bei einer $t e / z u$-Infinitivgruppe (vgl. 4.2.1.2.3.)

- bei Nebensätzen (auch Relativsätzen):

was die bereits bellwache und unternebmungslustige Maus nach der Ausspracbe zu jener Katze sagen würde, die zwar ausgestopft war aber immer noch schlich (GG 117)

wat de al klaarwakkere en ondernemende muis na bet onderboud tegen die kat zou zeggen, die weliswaar opgezet was, maar nog altijd sloop

Einige Nebensätze können nicht im 3. Stellungsfeld vorkommen, wie die Objektsätze und Subjektsätze, die mit daß eingeleitet sind: meistens stehen sie im 5. Stellungsfeld:

ich will docb nicht glauben müssen, daß Sie nur Mablke wegen wieder vor dem Altar dienen wollen (GG 88)

Ik boef toch boop ik niet aan te nemen dat je alleen om Mablke weer voor bet altaar wilt dienen

Sie können aber auch im 1. Stellungsfeld stehen:

daß Sie ... dienen wollen, will ich docb nicht glauben müssen dat je ... wilt dienen, boef $i k$ toch boop ik niet aan te nemen

Bei den mit zodat/so daß eingeleiteten Konsekutivsätzen ist auch die Voranstellung ausgeschlossen (vgl. 1.3.2.); sie können also nur im 5. Stellungsfeld stehen.

- bei Satzgliedern, die aus mehreren nebengeordneten Teilen bestehen. Bisweilen stehen alle nebengeordneten Teile im 5. Stellungsfeld:

Een goede verbandeling moet bestaan uit een inleiding, een midden en een slot 
Eine gute Abbandlung muß besteben aus einer Einleitung, einer Mitte und einem Schluß

Wie aus folgendem Beispiel hervorgeht, ist das aber nicht notwendig:

Hij ging met zijn vriend wandelen en met diens zuster Er ging mit seinem Freund spazieren und mit dessen Scbwester

- bei längeren Satzgliedern, vor allem Präpositionalgruppen:

tot een naspel, dat tenslotte potsierlijk en beledigend zal zijn tot in de verste achtergronden (HM 135)

zu einem Nachspiel, das schließlich possenbaft und beleidigend sein $m u \beta$ bis in die fernsten Hintergrïnde

In vielen Fällen wird die Präpositionalgruppe noch näher bestimmt durch einen Relativsatz:

terwijl bij aanhoudend vordert op de weg, waarvan bet doel in een wezenloos verschiet blijft liggen (HM 15)

wäbrend er immer weiter wandert auf dem Wege, dessen Ziel in einer unwirklicben Ferne bleibt

5.1.3. Auch die meisten Vergleichselemente stehen gewöhnlich im 5. Stellungsfeld, selbst wenn sie nicht lang sind. Das scheint ihre normale Stellung zu sein (vgl. Engel, 1970a, S. 92):

einen Teil unserer Studienräte, die schon zu seiner Zeit dieselben Spitznamen gebabt batten wie zu unserer Zeit (GG 51) enkele van de leraren, die in zijn tijd al dezelfde bijnamen hadden gebad als in de onze

5.1.4. Ungewöhnlich ist die Stellung eines Subjekts oder eines direkten Objekts im 5. Stellungsfeld, auch wenn dies relativ lang ist:

Toen boden zich aan (:) drie jongens en een meisje

Dann boten sich an (:) drei Jungen und ein Mädchen

Dit beeft tot doel gehad een betere verdeling der goederen

Das bat zum Ziel gebabt eine bessere Verteilung der Güter

Weiter kommen auch kurze Elemente wie Adverbien selten im 5. Stellungsfeld vor:

Het is warm vandaag

Es ist warm beute 
5.1.5. Daß ein Element aus der Satzklammer gelöst wird, kann zwei verschiedene Gründe haben (vgl. Engel, 1970a, S. 91 - 92).

5.1.5.1. Was im 5. Stellungsfeld steht, wird sozusagen nachher hinzugefügt, ist ein Nachtrag. Das ist oft der Fall bei Adverbien und bei Elementen, die einem schon in einem anderen Stellungsfeld stehenden Satzglied nebengeordnet sind.

5.1.5.2. Das außerhalb der Satzklammer stehende Element kann aber auch, gerade durch seine Stellung, besonders hervorgehoben sein. Das gilt für notwendige Verbergänzungen wie das Subjekt, das direkte Objekt oder auch das Präpositionalobjekt.

5.2. Wie aus den oben angeführten Beispielen hervorgeht, verfügen das Deutsche und das Niederländische hier ganz allgemein über dieselben Stellungsmöglichkeiten. Der Unterschied liegt darin, daß, wie Van Haeringen bemerkt (1956, S. 90), "das Niederländische mehr als das Deutsche geneigt ist, die Spannung, die größer wird, je nachdem die zwischen dem finiten Verb und dem Subjekt stehenden Satzglieder umfangreicher werden, ein wenig zu erleichtern". (Was Van Haeringen hier über den Formnebensatz sagt, gilt mutatis mutandis natürlich auch für den Formhauptsatz.)

Fälle wie:

ging sodann zum nervösen Ablesen der Zeit über (GG 75) en ging toen over tot bet nerveuze aflezen van de tijd

Dronken van woorden en liturgie viel bij binnen in verboden bacchanalia (HM 54)

Trunken von Worten und Liturgie bracb er in verbotene Bacchanalien ein

sind relativ leicht zu finden.

Aus diesem Unterschied in der Frequenz, worüber leider noch keine statistischen Untersuchungen vorliegen, aber - wie Labroisse (1956, S. 168) - zu schließen, die Satzstruktur des Niederländischen stehe der des Englischen (mit zusammenstehenden Verbformen) näher als der des Deutschen, scheint uns grundsätzlich falsch zu sein.

Wie ist nun die stärkere Abneigung gegen die Ausklammerung im Deutschen zu erklären? Wir glauben, diese Haltung auf den Einfluß der nor- 
mativen deutschen Grammatik zurückführen zu können. Diese hat seit dem 16. Jahrhundert immer wieder die absolute Endstellung der zum 4. Stellungsfeld gehörenden Verbformen vorgeschrieben und auf diese Weise die Schriftsprache bis vor kurzem beeinflußt. So schrieb K. Boost, ein Beispiel von E. Drach zitierend, noch:"Dieser auch bei Gliedsätzen auftretende Nachtrag: "Als wir vor der Hütte ankamen mit Schneeschuhen und Lebensmitteln, war die Türe verschneit" bedeutet eine gewollte oder bei sprachlicher Nachlässigkeit oder Unfähigkeit ungewollte Abweichung vonder Norm, die a ch als solche empfunden wird" (1964, S. 63, gesperrt von uns). In der niederländischen Grammatik dagegen wurde der Wortstellung bis vor kurzem fast keine Aufmerksamkeit gewidmet, so daß auch das Prinzip der Satzklammer nicht beschrieben wurde und also auch keine Regel bestehen konnte, die die Ausklammerung verbot. Daß die deutschen Grammatiker aber eine künstlich eingeführte Regel verteidigten, die im Gegensatz zum Sprachgebrauch stand, wurde in letzter Zeit mehrmals betont (vgl. Admoni, 1962, S. 169; von Polenz, 1964, S. 86 - 90; Beneš, 1968b, S. 291 - 294; Stolt, 1966, S. 10 - 13). Den überzeugendsten Beweis gegen die weitverbreitete Meinung, die Ausklammerung komme vor allem in jüngster Zeit vor (vergleiche noch Sommerfeldt-Pfeffer, 1963, S. 65: "Unserer Meinung nach ist es notwendig, daß wir uns mit der Ausklammerung aus dem verbalen Rahmen befassen, da gerade sie zu den sprachlichen Mitteln gehört, die sich sehr schnell verändern") bietet wohl die Untersuchung von Texten des 17. bis 20. Jahrhunderts durch Engel; daraus geht hervor, daß gerade in dem neuesten der 10 untersuchten Texte (G. Grass, Katz und Maus) die wenigsten Ausklammerungen vorkommen (Engel, 1970b, S. 56).

5.3. Auch wenn das 4. Stellungsfeld leer ist, kann der Formhauptsatz ein 5. Stellungsfeld enthalten. Das wird klar, wenn die einfache Verbform durch eine zusammengesetzte ersetzt wird (vgl. Nieuwborg, 1968, S. 49 - 50; Engel, 1970a, S. 34):

we eten vis vandaag wir essen Fisch beute

gegenüber:

we bebben vis gegeten vandaag wir haben Fisch gegessen beute 
Auf dieses Problem wollen wir hier aber nicht näher eingehen.

\section{Zusammenfassung}

Aus dem Vorhergehenden kann geschlossen werden, daß der niederländische und der deutsche Satz dasselbe Strukturprinzip haben, daß sie aber in einigen Punkten mehr oder weniger voneinander abweichen. Die meisten hier angegebenen Regeln oder Tendenzen müssen aber als vorläufig betrachtet werden: sie sind das Ergebnis einer ersten Beschäftigung mit der Wortstellung des Deutschen und des Niederländischen. Dies möge eine Erklärung (und eine Entschuldigung) sein für den stellenweise vielleicht unausgeglichenen Aufbau des Ganzen. Es müssen, besonders fürs Niederländische, noch viele Einzeluntersuchungen durchgeführt werden, bevor definitive Ergebnisse vorgelegt werden können.

\section{L i t e r a tur}

Es wird jeweils die Auflage angegeben, nach der zitiert wurde. Wo es uns wichtig erschien, wird auch das Erscheinungsjahr der ersten Auflage genannt.

Admoni, W. (1962), Die umstrittenen Gebilde der deutschen Sprache von heute, in: Muttersprache 72, S. $161-171$.

Auerbach, T. (1960), Leserbrief in Lebhafter Meinungsstreit um eine Grundfrage des deutschen Satzes, in: Sprachpflege 9, S. 14 - 16.

Bauwens, V. (1964), De aanloop in de mededelende hoofdzin in het Nederlands (Dissertation, Gent).

Bech, G. (1952), Uber das niederländische Adverbialpronomen ER (CopenhagueAmsterdam).

Behaghel, O. (1932), Deutsche Syntax. Eine geschichtliche Darstellung, Bd. IV (Heidelberg).

Beneš, E. (1968a), Die funktionale Satzperspektive im Deutschen und im Tschechischen, in: Deutsch-Tschechische Beziehungen im Bereich der Sprache und Kultur. Aufsätze und Studien II (Berlin), S. 57 - 69.

- - (1968b), Die Ausklammerung im Deutschen als grammatische Norm und als stilistischer Effekt, in: Muttersprache 78, S. $289-298$. 
Berg, van den, B. (1967), Bijdragen tot de syntaxis van het Nederlands IV, in: De nieuwe taalgids $60, \mathrm{~S} .305-312$.

Bodmer, F. $\left(1961^{7}\right)$, The Loom of Language (London, 1943 ${ }^{1}$ ).

Boost, K. $\left(1964^{5}\right)$, Neue Untersuchungen zum Wesen und zur Struktur des deutschen Satzes (Berlin, 1951 $1^{1}$ ).

Cubber, de, W. (1968), De splitsing van scheidbaar samengestelde werkwoorden in hedendaags proza (Dissertation, Gent).

Drach, E. $\left(1963^{4}\right)$ Grundgedanken der deutschen Satzlehre (Darmstadt, $1937^{1}$ ).

Engel, U. (1970a), Regeln zur Wortstellung, in: Forschungsberichte des Instituts für deutsche Sprache 5, S. 3 - 148.

- - (1970b), Studie zur Geschichte des Satzrahmens und seiner Durchbrechung, in: Studien zur Syntax des heutigen Deutsch (= Sprache der Gegenwart, Bd. 6, Düsseldorf), S. 45 - 61.

Erben, J. (1967 $\left.{ }^{10}\right)$, Abriß der deutschen Grammatik (Berlin, 1958 ${ }^{1}$ ).

Es, van, G. (1970), Functies en structuren van de reflexieve verbinding in het Nederlands, in De nieuwe taalgids, Van Haeringennummer, S. 21 - 42.

Flämig, W. (1964), Grundformen der Gliedfolge im deutschen Satz und ihre sprachlichen Funktionen, in: Beiträge zur Geschichte der deutschen Sprache und Literatur 86 (Halle), S. $309-349$.

Grebe, P. (Hrsg.) $\left(1966^{2}\right)$, Grammatik der deutschen Gegenwartssprache = Der Große Duden, Bd. 4 (Mannheim, 19591).

Haeringen, van, C.B. (1947), "Tangconstructies" en reacties daarop, in: De nieuwe taalgids 40, S. 1 - 7 .

- - , (1956), Nederlands tussen Duits en Engels, in: A]gemene aspecten van de grote cultuurtalen, S. 27 - 97 (Den Haag).

Hejbig, G. - Schenkel, W. (1969), Wörterbuch zur Valenz und Distribution deutscher Verben (Leipzig).

Jørgensen, P. (1964), Tysk Grammatik III, i samarbejde med Ove K. Clausen (Kobenhavn).

Koelmans, L. (1965), lets over de woordorde bij samengestelde predikaten in het Nederlands, in: De nieuwe taalgids 58, S. $156-165$.

- , (1970), Zinnen met aanloop in het Nederlands, in: De nieuwe taalgids 63 , S. 21 - 27.

Kufner, H.L. $\left(1963^{2}\right)$, The Grammatical Structure of English and German (Chicago-London). 
Labroisse, G. (1956), Zum Charakter der niederländischen und deutschen Hochsprache. Studie zur Eigenständigkeit des Niederländischen (Doktorarbeit, Berlin).

Leys, O. (1970), Die Präpositionalinfinitive im Deutschen. Einige Beobachtungen, in: Leuvense Bijdragen 60, S. 1 - 56.

Mars, F.K.M. (1970), Syntactische Brabantismen, in: De nieuwe taalgids 63, S. 32 - 38.

Mattausch, J. (1965), Untersuchungen zur Wortstellung in der Prosa des jungen Goethe (Berlin).

Merckens, P.J. (1960), De plaats van de persoonsvorm, een verwaarlopsd codeteken, in: De nieuwe taalgids 53, S. 248 - 254.

Möller, G. $\left(1965^{3}\right)$, Deutsch von heute (Leipzig).

Nieuwborg, E. (1968), De distributie van her onderwerp en het lijdend voorwerp in het huidige geschreven Nederlands in zijn A.B.-vorm (Antwerpen).

Neumann, W. (1961), Zur Struktur des Systems der reinen Kasus im Neuhochdeutschen, in: Zeitschrift für Phonetik, Sprachwissenschaft u. Kommunikationsforschung 14, S. 55 - 63.

Ostendorp, M.A.F. (1958), De tangconstructie als syntactisch stramien, in: De nieuwe taalgids 51, S. $139-144$.

Overdiep, G.S. $\left(1949^{2}\right)$, Stilistische grammatica van het moderne Nederlandsch, 2e druk bezorgd door G.A. Van Es (Zwolle).

Paardekooper, P.C. (1955), Syntaxis Spraakkunst en Taalkunde (Den Bosch).

- - , $\left(1968^{3}\right)$, Beknopte ABN-syntaksis (Den Bosch).

Pauwels, A. (1953), De plaats van hulpwerkwoord verleden deelwoord en infinitief in de Nederlandse bijzin. 2 Teile. (Leuven).

Pauwels, J.L. $\left(1959^{4}\right)$, Les difficultés de la construction de la phrase néerlandaise (Liège).

- - (1965), De volgorde van verbogen verbale vormen in het Nederlands, in: Dietse Studies. Bundel aangebied aan Prof. Dr. J. Du P. Scholtz by geleentheid van sy vyf-en-zestigste verjaardag (Assen-Kaapstad Pretoria).

- - (1970), Statistisch onderzoek van de Nederlandse zinsbouw, in: De nieuwe taal gids, Van Hacringennummer, S. $93-100$.

Polenz, von, P. (1964), Sprachnormung und Sprachentwicklung im neueren Deutsch, in: Der Deutschunterricht 16, H. 4., S. 67 - 91. 
Polenz, von, P. (1966), Zur Quellenwahl für Dokumentation und Erforschung der deutschen Sprache der Gegenwart, in: Wirkendes Wort 16, S. 3 - 13.

Rath, R. (1965), Trennbare Verben und Ausklammerung. Zur Syntax der deutschen Sprache der Gegenwart, in: Wirkendes Wort 15, S. 217 - 232.

Riesel, E. (1963 2 ), Stilistik der deutschen Sprache (Moskau).

Rijpma, E. - Schuringa, F.G. $\left(1969^{2}\right)$, Nederlandse Spraakkunst, bewerkt door J. Van Bakel (Groningen).

Sassen, A. (1963), Endogeen en exogeen taalgebruik, in: De nieuwe taalgids 56, S. 10 - 21.

Schulz, D. - Griesbach, H. $\left(1970^{8}\right)$, Grammatik der deutschen Sprache. Neubearbeitung von $\mathrm{H}$. Griesbach (München).

Schutter, de, G. (1964), De dubbele werkwoordgroep in het Nederlands, in: Studia Germanica Gandensia VI, S. 45 - 87.

- -, (1967), Principes van de woordvolgorde in de Nederlandse zin, in: Handelingen van het 26e Vlaams Filologencongres (Gent).

- - (1970), Pronominale problemen in de syntaxis van de Zuidnederlandse dialekten, in: Taal en Tongval 22, S. $151-182$.

Smet, de, J. (1970), Gerade und ungerade Stellung in der modernen deutschen Prosa (Dissertation, Gent).

Sommerfeldt, K.-E. (1966), Zum Vorfeld im Aussagesatz, in: Sprachpflege 15, S. $129-132$.

Sommerfeldt, K.-E. - Pfeffer, E. (1963), Tendenzen der Ausklammerung der deutschen Gegenwartssprache, in: Sprachpflege 12, S. 65 - 68.

Stolt, B. (1966), Der prädikative Rahmen und die Reihung (= Moderna Sprák, Language monographs 9).

Stroop, J. (1970), Systeem in gesproken werkwoordsvormen, in: Taal en Tongval 22 , S. $128-147$.

Vanacker, V.F. (1964), Is het algemeen Zuidnederlands? in: Taal en Tongval 16, S. $159-164$.

- - (1970a), Een Zuidnederlandse konstruktie in een paar Zuidnederlandse dialekten, in: De nieuwe taalgids, Van Haeringennummer, S. 140 - 157.

- - , (1970b), Een paar punten uit een vergelijkend syntaxisonderzoek van enkele Zuidnederlandse dialekten, in: Zijn akker is de taal (Den Haag), S. 291 - 303. 
Velde, van de, M. (1967), Enkele tendensen in de woordvolgorde in modern Nederlands proza, in: Studia Germanica Gandensia IX, S. 129 - 156.

- , (1969), De doorbreking van de werkwoordelijke eindgroep in literair proza, in: Studia Germanica Gandensia XI, S. 7 - 31.

Vindevogel, T. (1966), Beknopte Duitse spraakkunst met oefeningen (Brussel).

Weisgerber, L. $\left(1967^{3}\right)$, Von den Kräften der deurschen Sprache, Bd. 2. Die sprachliche Gestaltung der Welt (Düsseldorf).

Winter, W. (1961), Relative Häufigkeit syntaktischer Erscheinungen als Mittel zur Abgrenzung von Stilarten, in: Phonetica 7, S. $193-216$. 